\title{
The Morphosyntax of Arabic Exceptives: A minimalist approach
}

\author{
Hussein Al-Bataineh \\ Memorial University of Newfoundland \\ hhalbataineh@mun.ca
}

February 14, 2020

\begin{abstract}
Arabic exceptive constructions involve an intricate interaction among word order, negation, and case assignment resulting from syntactic restrictions imposed on the argumental, appositional, and adjunctive functions of exceptive phrases. The morphosyntactic complexities in Arabic exceptives cast doubt on the adequacy of previous analyses that exceptive particles are prepositions, focal adverbs, or coordinating conjunctions, and they also lead the paper to argue for more principled accounts in which exceptive particles are analyzed as functional heads that project into an ExP 'exceptive phrase' which exists in two distinct configurations. The first includes an exceptive marker carrying [Acc-Case] 'accusative case' and [DS] 'domain subtraction' features when the ExP is an adjunct introduced by late Merge. The second includes a negative determiner which selects and c-commands the exceptive particle and deactivates/ suspends its [Acc-Case], consequently, the case feature of the ExP-complement is valued by percolation from $\mathrm{D}$ which combines with the exceptive marker to form a discontinuous focus particle with a [DR] 'domain restriction' feature.
\end{abstract}

Keywords: adjunction, case valuation, conjunction, ellipsis, exception, feature percolation, negation

\section{Introduction}

An exceptive phrase is a 'subordinate clause functions to present an exception to an idea, action, or situation that is presented in the main clause' (Arnold \& Choi, 2018:193). The exceptive element but (and also except, except for and only) in sentences like (1a,b) below is used to express restriction or, according to von Fintel (1993:126), to create domain subtraction:

1) a. Every student but John attended the meeting.

b. No student but John attended the meeting.

(von Fintel, 1993:124)

But in these sentences is used to subtract entities from the domain of a quantifier like every or no, that is, it is utilized to reduce or restrict the domain of the qualification, and this restrictive behavior is assumed to be shared by all exceptive constructions (for the semantics of exceptives, see, for example, von Fintel \& Iatridou, 2007; Moltmann, 1995; Xiang, 2017, for an overview, see Gajewski, 2008). According to von Fintel \& Iatridou (2007:446-447), exceptive phrases are constructed cross-linguistically by using an element like only (2a) or NEG+ EXCEPTIVE (2b): 
2) a. Only John came. (languages like German, Finnish, Spanish, Tagalog, etc.)

b. Nobody came except John. (languages like Greek, French, Irish, Hebrew, etc.)

The Arabic language is similar to languages in $(2 b)$ in the sense that exceptive phrases are used in negative sentences with the particle 'illa 'except', but it is different from the closely related Semitic language, Hebrew, because Arabic exceptives can also be used in affirmative sentences (cf., Zewi, 1998:546) as in (3):

3) 'tā al-jamii'-u 'illa zayd-a-n came DEF-all-NOM except Zayd-ACC-INDEF ${ }^{1},{ }^{2}$

'All came except Zayd.'

Apart from the extensive debates on the semantics of exceptives, only a few syntactic studies are devoted to the topic (e.g., O’Neill 2014; Pérez-Jiménez and Moreno-Quibén 2012; Potsdam and Polinsky 2017; Sava 2009; Soltan 2016). These studies argue that exceptive particles can be prepositions, focal adverbs, or conjunctions that conjoin either two DPs (in the case of connected exceptives) or two CPs (in cases of free exceptives) assuming a process of ellipsis to take place. However, this paper discusses and dismisses previous proposals in the literature and argues that they fail to account for Arabic exceptives. The paper claims that the distributional facts of Arabic exceptives and their idiosyncrasies cannot be captured by sentential/ellipsis analysis, contra Soltan (2016). To briefly explain some of these intricacies and perplexing properties, consider (4a-c) which exemplify the three functions of exceptives, viz., argumental, appositional, and adjunctive, respectively.

4) a. mā hadara 'illā țālib-u-n

not came except student-NOM-INDEF

'Only one student came.'

(Alhawary 2011:310)

b. mā hadara 'ahad-u-n

not came one-NOM-INDEF

'illā tạlib-u-n/ țālib-a-n

'No one came except a student.'

except student-NOM-INDEF/ student-ACC-INDEF

\section{c. hadarara al-jamii'-u, 'illā tâlib-a-n \\ came DEF-all-NOM except student-ACC-INDEF}

'All came except one student.'

These sentences represent three syntactic configurations in which case is realized differently. Although the excepted noun țālib 'student' occupies the same position after the exceptive particle

\footnotetext{
${ }^{1}$ I consider nunation $-n$ as an indefinite article, that is, it is a determiner like the definite article al-for two reasons. (i) The definite article al- and nunation $-n$ are in complementary distribution (*al-walad-u-n "the a boy'). (ii) Both $a l$ - and $-n$ cannot occur in annexation (i.e., attachment to a pronoun) *al-walad-u-k / *walad-u-n-k, or in the construct state like *al-șadiiq-a amrin / *sadiiq-a-n amrin (Al-Ansari, 1991:740, cited in Al-Bataineh 2020b).

${ }^{2}$ I use the following abbreviations: ACC: accusative; DEF: definite article; FEM: feminine; GEN: genitive; INDEF: indefinite article; MASC: masculine; NOM: nominative; PL: plural; SG: singular. 1, 2, 3: first, second, third person, respectively. In the transliteration, the dot under the letter indicates that the sound is emphatic and pharyngealized; [t], [ḍ], and [s] are the emphatic counterparts of [t], [d], and [s], respectively (for an overview, see, Al-Bataineh 2019).
} 
'illā, it has only the nominative case in (4a), either nominative or accusative in (4b), and only accusative in (4c). Additionally, the exceptive phrase can be fronted only in (4c), but not in (4a) or (4b). These facts (and other idiosyncrasies to be explained below) cast doubt on the adequacy of the previous proposals in the literature regarding the categorial status of exceptive particles and their analyses. The paper departs from the mainstream literature and tests the hypothesis that exceptive particles are functional heads that are base-generated in Ex 'exceptive head' which projects into an ExP, rather than a PP, an AdvP, or a ConjP. The paper argues that this hypothesis is more strongly supported by the data and more plausible to account for different positions, case alternations, and other intricacies in Arabic exceptive phrases.

The rest of the paper is organized as follows: Section 2 provides a detailed description of Arabic exceptives. Section 3 considers the categorial status of Arabic exceptive particles and shows how the coordination hypothesis is inadequate for explaining the full range of data. Section 4 considers the different functions/ positions of exceptive phrases in negative and affirmative sentences that correlate with the case assignment. Section 5 summarizes and concludes the paper.

\section{Exceptive Constructions in Arabic}

The so-called 'istitn $\bar{a}$ ' 'exceptive construction' exists in all varieties of Arabic, i.e., Classical Arabic (CA), Modern Standard Arabic (MSA), and colloquial varieties. The syntactic properties of exceptive constructions seem to be the same in all Arabic varieties. Comparing the structure in CA (see, Zabarah, 2017, for a detailed overview) with that of MSA (e.g., Badawi, Carter, and Gully 2015; Ryding 2005; Alhawary 2011) shows that both CA and MSA have the same syntax of exceptives. Consider (5a,b) from CA and MSA, respectively, and notice that exceptive constructions include three main parts: the exceptive particle illa 'except'; the mustatnā 'excepted noun' or the noun after 'illā; and the mustatnā min-hu 'noun excepted from' or the noun before 'illā (I will use the abbreviation ExP for 'exception phrase', ExP-complement for 'the excepted noun', ExP-associate for 'the associate of the exception phrase (the noun excepted from)':
5) a.jā'a-nì
al-qawm-u
'illā zayd-a-n
came-me DEF-people-NOM
except Zayd-ACC-INDEF
'People came to me except Zayd.'
b. $j \bar{a} ' a$
kull-u
aț-tullāb-i
came all-NOM
DEF-students-GEN
'illā naj̄̄b-a-n
except Najib-ACC-INDEF
'All the students came except Najib.'

(Ibn Ya'īsh 2001:46)

(Ryding 2005:651)

In (5a,b), 'illā 'except' mediates between the Ex-associates alqawmu 'the people' and kullu attulläbi 'all the students' and the Ex-complements zaydan 'Zayd' and najīban 'Najib', respectively. Parallel structures also exist in colloquial varieties. Consider the equivalents of (5a,b) below from Jordanian Arabic (JA) (for more examples from Egyptian and Palestinian Arabic, see Soltan 2016 and Khalaily 2019).

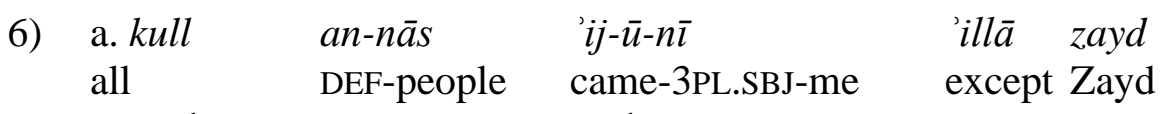
'People came to me except Zayd.' 


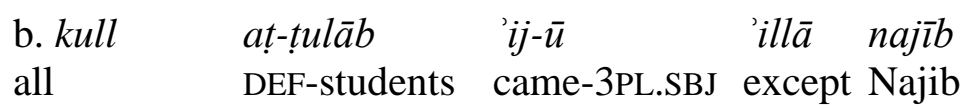

'All the students came except Najib.'

Generally speaking, standard varieties (i.e., CA and MSA) and colloquial dialects (e.g., JA) have the same syntax (or at least profound similarities) of exceptive constructions ${ }^{3}$. Based on this assumption, the paper focuses on CA and MSA, rather than on colloquial dialects, because only the standard varieties can provide an accurate, comprehensive description of exceptive constructions as they are the only ones with rich inflectional morphology that is essential for determining the syntactic status of the ExP components in a particular structural domain. Compare, for example, the presence of case endings on nominals in $(5 a, b)$ and their absence on the same nominals in $(6 a, b)$.

Returning to the main components of exceptive constructions, the ExP-associate is optional and can be omitted without affecting the well-formedness of negative sentences. The only obligatory elements are the particle 'illa and the ExP-complement, as demonstrated in (7a-c).

7) a. mā hadara 'illā tạlib-u-n not came except student-NOM-INDEF 'Only one student came.'

(Alhawary 2011:310)

b. $m \bar{a}$ qābal-tu 'illā țālib-a-n not met-1SG.SBJ except student-ACC-INDEF 'I met only one student.'

(Alhawary 2011:310)

c. $m \bar{a}$ astama'-tu 'illā 'ilà tālib-i-n not listened-I except to student-GEN-INDEF 'I listened only to one student.'

(Alhawary 2011:310)

Apart from providing restrictive meaning, the exceptive particle along with the negative element $m \bar{a}$ 'not' act as if they are not there. The absence of any syntactic effect of 'illa and $m \bar{a}$ can be seen in the inflectional endings of $t \bar{a} l i b$ which takes the nominative, accusative, and genitive case in (6a-c) due to its role as subject, object, and object of the preposition, respectively. However, the optionality of the ExP-associate is only possible in negative sentences since the equivalent affirmative sentences of (7a-c) are ungrammatical (see, e.g., Zabarah 2017:149; Moutaouakil 2009:85).

8) a. * hậ̣ara 'illā tâlibun

b. * qābaltu 'illā țāliban

c. * astama 'tu 'illā 'ilā țālibin

The ungrammaticality of $(8 \mathrm{a}-\mathrm{c})$ is related to the requirement that the ExP-associate cannot be deleted when the negative particle is absent. This correlation between the ExP-associate and the negative particle seems well established as evidenced in the fact that other negative particles have the same effect. Consider the obligatory presence of $l \bar{a}$ and $l a m$ in $(9 \mathrm{a}, \mathrm{b})$.

3 This assumption is based on the author's intuition as a native speaker of JA and his consultation with speakers of other colloquial dialects such as Libyan, Yemeni, and Syrian Arabic. 
$\begin{array}{llll}\text { 9) } *(l \bar{a}) & \text { 'ahad-a } & \text { fi-hā } & \text { 'illā zayd-u-n } \\ \text { not } & \text { one-ACC } & \text { in-it } & \text { except Zayd-NOM-INDEF }\end{array}$

'No one is there except Zayd.'

(Zabarah, 2017:146) $\begin{array}{llll}\text { b. *(lam) } & \text { ya-qum } & \text { 'ahad-u-n ' } n \text { 'illa } & \text { zayd-u- } n \\ \text { not } & \text { he-stood } & \text { one-NOM-INDEF except } & \text { Zayd-NOM-INDEF }\end{array}$

'No one stood except Zayd.'

(Zabarah, 2017:157)

Moreover, these sentences indicate that when the ExP-associate is indefinite or unspecific (e.g., 'ahad 'one'), it must be preceded by a negative element that licenses its existence. To sum up, if the ExP-associate is absent or indefinite, the sentence must be negative. In addition to cases of noun phrases, the ExP-associate can also be a prepositional phrase (10a) or a clause (10b):

10)

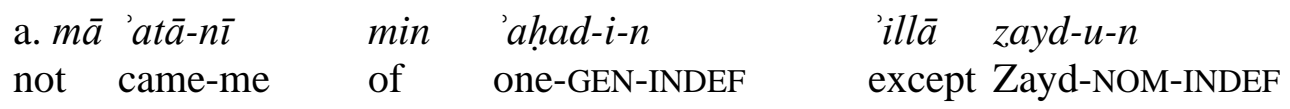

'None of them came to me except Zayd.'

(Zabarah, 2017:146)

b. $m \bar{a}$ 'alim-tu 'anna fi-hā 'illā zayd-a-n

not knew-I that in-it except Zayd-ACC-INDEF

'I did not know anyone was there except Zayd.'

(Zabarah, 2017:146)

Regarding grammatical inflection of the ExP-complement, there are two options when the sentence is negated; either the nominal expression has the inflection of the ExP-associate in badal 'apposition' constructions ${ }^{4}$, or it has the accusative case. In badal constructions, the two nouns have the same inflection since 'both nouns are equal in status and one can replace the other' (Zabarah, 2017:144). Consider case variation in (11a,b):
a. $m \bar{a}$ qadima al-kuttāb-u
'illā zayd-u-n/
zayd-a-n
not came DEF-writers-NOM except Zayd-NOM-INDEF/
Zayd-ACC-INDEF

'The writers did not come except for Zayd.'

(Moutaouakil 2009:89)

b. $m \bar{a}$ astama'-tu 'ilā aṭ-tullāb-i
not listened-I to DEF-students-GEN
wāhid-a- $n$
one-ACC-INDEF
'I didn't listen to the students except for one.'

'illā wāḥid-i-n/

except one-GEN-INDEF/

wăhid-a- $n$

one-ACC-INDEF

(Alhawary 2011:309)

In (11a), zayd is nominative because it is in an appositional relationship with alkuttābu 'the writers', that is, zayd refers to alkuttābu and agrees with it in the nominative case, and in (11b), wähid 'one' has the genitive case as ațtullābi 'the students' for the same reason. In both (11a,b), the exceptive construction may form an independent phrase; consequently, the Ex-complement has an accusative case regardless of the inflection of the ExP-associate.

If the exceptive phrase is fronted, only the accusative case can be assigned (i.e., badal construction is ruled out). Consider (12a,b):

\footnotetext{
${ }^{4}$ Badal 'apposition, substitution' refers to constructions where two noun phrases 'are juxtaposed and both refer to the same entity [....and they] agree in case, number, gender and definiteness' (Ryding, 2005: 224).
} 


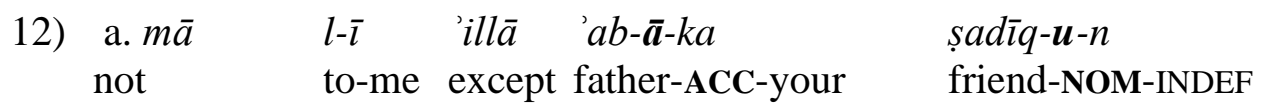

'No one is there for me except your father as a friend.'

(Zabarah, 2017:150)

$\begin{array}{llll}\text { b. } * m \bar{a} & l-\bar{l} & \text { 'ill } \bar{a} \quad \text { 'ab- } \overline{\boldsymbol{u}}-k a & \text { sadi } q-\boldsymbol{u}-\boldsymbol{n} \\ \text { not } & \text { to-me } & \text { except father-NOM-your } & \text { friend-NOM-INDEF }\end{array}$

'No one is there for me except your father as a friend.'

(12b) is ungrammatical because the ExP-complement ' $a b$ 'father' is assigned the nominative case (realized as $-u$ in ' $a b-\bar{u})$ ) rather than the accusative case.

While in negative sentences both badal and the accusative are feasible options, in affirmative sentences only the accusative is possible, as can be seen in the contrast in (13a,b):
a. qadima al-kuttāb-u
DEF-writers-NOM
'illā zayd-a-n
came
except Zayd-ACC-INDEF

'All the writers came except Zayd.'

(Moutaouakil 2009:87)
b. * qadima
al-kuttāb-u
'illā zayd-u-n
came
DEF-writers-NOM
except Zayd-NOM-INDEF

To sum up, exceptive constructions have the following syntactic properties. The exceptive particle 'illā has no obvious syntactic function in negative sentences lacking the ExP-associate, but in other constructions it seems to have. Only in negative sentences, the ExP-associate is optional and can be omitted without affecting the well-formedness of the sentence. Regarding the grammatical inflection of the ExP-complement, there are two options when the sentence is negated, either it has the inflection of the ExP-associate in badal 'apposition' constructions, or it has the accusative case, but if the sentence is affirmative or the ExP is fronted, only the accusative case is possible. As highlighted above, these properties do not exist only in Arabic standard varieties (i.e., CA and MSA) but also in colloquial dialects as well. Apart from case alternation that cannot be investigated due to the impoverished inflectional morphology in Arabic dialects (i.e., the absence of case endings on both the ExP-associate and the ExP-complement), all the mentioned characteristics exist in the colloquial varieties. Consider, for example, ExPs in badal 'apposition' constructions, the obligatory presence of the negative particle, the possibility of fronting the ExP in (14a-c), respectively (for more examples from Palestinian Arabic, see Khalaily 2019).

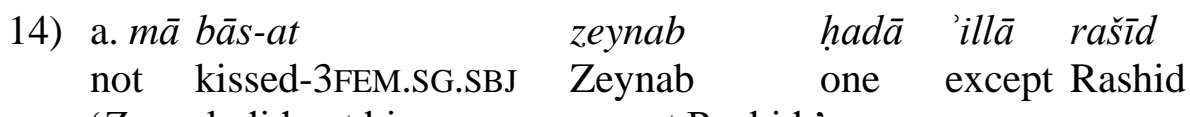

'Zeynab did not kiss anyone except Rashid.'

(Khalaily 2019:4)

$\begin{array}{llll}\text { b. }{ }^{*}(m \bar{a}) & b \bar{a} s \text {-at } & \text { zeynab } & \text { 'illā rašì } \\ \text { not } & \text { kissed-3FEM.SG.SBJ } & \text { Zeynab } & \text { except Rashid }\end{array}$

'Zeynab only kissed Rashid.'

(Khalaily 2019:1)

c. 'illā rašì mā bās-at zeynab

except Rashid not kissed-3FEM.SG.SBJ Zeynab

'Only Rashid did Zeynab not kiss.'

(Khalaily 2019:2) 
However, the syntactic characteristics of exceptive constructions lead us to doubt the explanation in the literature that exceptive particles can be analyzed as prepositions, focal adverbs or coordinating conjunctions simply because the perplexing intricacies discussed above do not exist in PPs, AdvPs or ConjPs. I argue that previous analyses do not suffice to handle the full range of data adequately and different proposals are needed.

\section{The Categorial Status of Arabic Exceptive Particle}

In order to account for the distributional properties of exceptive constructions, we first need to understand the syntactic nature of 'illa and determine its categorial status. To my best knowledge, three proposals are discussed in the literature; exceptive particles are argued to be prepositions, focal adverbs, or conjunctions. These proposals are discussed in Pérez-Jiménez \& Moreno-Quibén (2012) for Spanish and adopted by Soltan (2016) for Egyptian Arabic.

Exceptive markers as prepositions: Soltan (2016) rightly concludes that exceptive markers in Arabic are not prepositions, based on three arguments. Firstly, unlike 'illā, prepositions can be followed by the clitic form of a pronoun, and never by the strong form. I argue that this fact is caused by the different case features carried by prepositions and 'illā. Whereas prepositions carry the [Gen-Case] that can be valued only with a clitic form, 'illā carries the [Acc-Case] that can be valued with either a clitic or a strong form because case valuation correlates with the morphological realization of the pronoun; while pronouns have one invariable clitic form that can be valued as nominative, accusative or genitive; hence, it can be a complement to both a preposition and 'illa , pronouns have only two strong forms that can be valued only as nominative or accusative, but not as genitive; hence, the strong form can be a complement of 'illa but not a preposition (cf., 'you' has only two strong forms, 'anta 'you.NOM' and 'iyāka 'you.ACC', but it does not have a strong form 'you.GEN'). Secondly, in contrast with 'illāa, a preposition like min 'from' cannot take a PP as a complement without restrictions; some PPs are allowed (min tahti alTawila 'from under the table'), others are not (*min fi al-kis 'from in the bag'). Thirdly, nominals after prepositions have one specific case (i.e., genitive), unlike those after 'illä which may bear any case in some constructions (e.g., 5 a-c above). Another point related to selectional properties can be added to Soltan's (2016) arguments. 'illā can select a CP, AP or AdvP as a complement, but a preposition cannot. This fact seems valid not only in Arabic (see, e.g., Ya'īsh, 2001:47) but also in other languages such as French (O’Neill, 2011:177), Spanish (Pérez-Jiménez \& MorenoQuibén, 2012:591), and Romanian (Ionescu, 2013:6) ${ }^{5}$.

Exceptive markers as focal adverbs: 'On the basis of their semantic properties (exclusion vs. inclusion) and participial origin' exceptive markers are considered by some researchers to be focal adverbs (Pérez-Jiménez \& Moreno-Quibén, 2012:594). This possibility is ruled out by Soltan (2016) for two reasons. Firstly, adverbs like hattā 'even' may appear in an initial position without restrictions, but 'illā may not. Secondly, hattā 'even' can precede or follow the noun (e.g., hattā Aḥmad / Aḥmad h̦attāa), but 'illā cannot ('illā Aḥmad / *Ahtmad 'illā).

Exceptive markers as coordinating conjunctions: drawing on Pérez-Jiménez \& MorenoQuibén's (2012) reasoning, Soltan (2016) claims that 'illā is a coordinating conjunction. He differentiates between two types of exceptive phrases; namely, connected exceptives that join two DPs (e.g., [DP everyone] except [DP John] passed.) and free exceptives that conjoin two CPs, 'the

\footnotetext{
${ }^{5}$ As correctly suggested by a reviewer, it is possible for a preposition like English before to select a CP as a complement when it functions as a temporal adverbial.
} 
exceptive markers select for a full-fledged $\mathrm{CP}$ as complement, whose null head (C) triggers a process of ellipsis in which all the syntactic material inside TP is marked for PF-deletion, except the remnant constituent(s)' (Pérez-Jiménez \& Moreno-Quibén, 2012:582), that is, in cases where the exceptive phrase is parenthetical or fronted (e.g., Except [CP John (didn't pass)], [CP everyone passed]). The following representations are illustrative (Soltan, 2016:46-47):

15) a. Connected exceptives

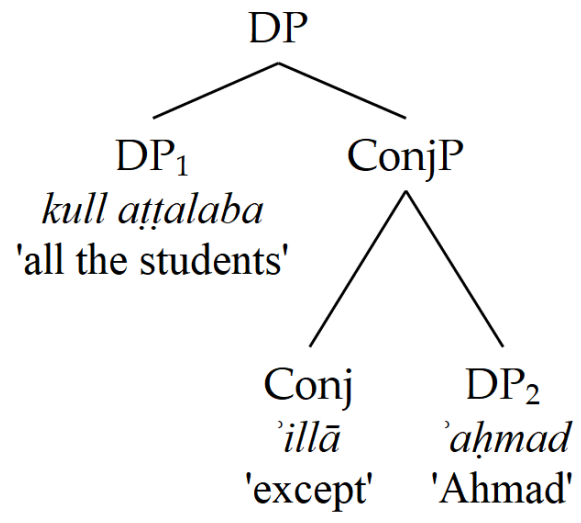

b. Free exceptives

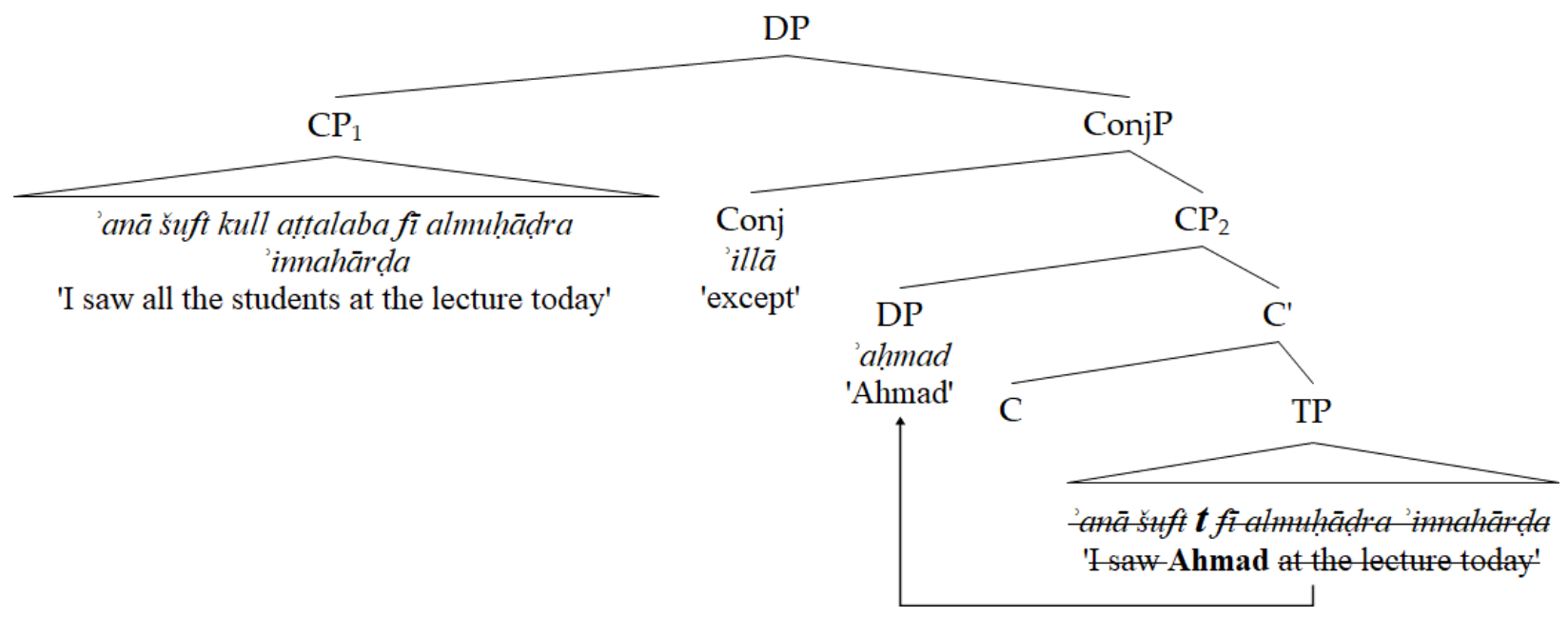

As highlighted in section (2), it is essential to consider the case endings of both ExP-associates and ExP-complements to reach an accurate, comprehensive analysis. Since colloquial dialects (including Egyptian Arabic) have impoverished inflectional morphology (i.e., they make no use of case markings on nominals), they are not ideally suited to the study of ExPs (and most probably to other studies focusing on case assignment, cf., vocatives and exclamatives in Al-Bataineh 2020a; 2020b), and it is essential to consider Standard Arabic varieties with rich morphology to avoid incorrect, implausible results. However, contra Soltan (2016), the data given above shows that exceptive constructions are not equivalent to conjunction phrases. There are multiple pieces of evidence indicating 'illā is completely different from Arabic conjunctions like wa 'and', aw 
'or', tumma 'then', $l \bar{a}$ 'not', etc ${ }^{6}$. First, conjunctions cannot assign case to the following noun, that is, they cannot carry a valued case feature like 'illa which can value an accusative case to ccommanded DP (i.e., the ExP-complement) in some constructions (for detailed analysis, see section (4.3) and (4.4) below). Consider (16a,b):
16) a. marar-tu
bi- 'așdiqa'-i
wa zayd-i-n
passed-I
by-friends.GEN-my and
Zayd-GEN-INDEF
'I pass by my friends and Zayd.'

\begin{tabular}{|c|c|c|}
\hline $\begin{array}{l}\text { b. marar-tu } \\
\text { passed-I }\end{array}$ & $\begin{array}{l}\text { bi- 'așdiqa'-i } \\
\text { by-friends.GEN-my }\end{array}$ & $\begin{array}{ll}\text { 'illā } & \text { zayd-a-n} \\
\text { except } & \text { Zayd-ACC-INDEF }\end{array}$ \\
\hline
\end{tabular}

While in (16a) the conjunction wa 'and' cannot value case on zayd, thus, zayd gets the same genitive case as 'așdiqa' 'friends' (the object of the preposition bi- 'by'), in (14b) the structure is different, and zayd is marked accusative, instead of genitive. If we assume zayd and 'așdiqa' are

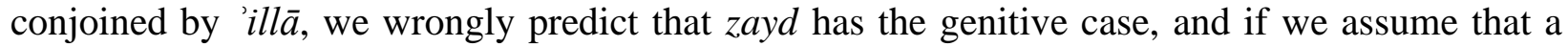
process of ellipsis takes place, and 'illā conjoins two CPs in which zayd is the remnant constituent after PF-deletion, we reach a worse result because the verb marartu 'I passed' is intransitive and does not value the accusative case on zayd (and if we suppose that zayd is the subject, it must be zayd-u- $n$ with the nominative ending $-\boldsymbol{u}$, contra to fact). The only plausible analysis at hand is that 'illā has a [Acc-Case] feature that is valued on zayd by Agree, and this feature cannot be carried by the conjunction wa 'and' or any coordinating conjunction not only in Arabic but also in other languages (see, e.g., Weisser 2019).

Second, while an ExP can be introduced into a negative sentence lacking the ExP-associate, a conjunction phrase cannot. Compare (17a) with (17b):

17) a. $m \bar{a}$ 'atā-nì 'illa zayd-u-n

not came-me except Zayd-NOM-INDEF

'None came to me except Zayd.'

(Zabarah, 2017:143)

$\begin{array}{llll}\text { b. }{ }^{*} m \bar{a} & \text { 'at } \bar{a}-n \bar{\imath} & \text { wa } & \text { zayd-u- } n \\ \text { not } & \text { came-me } & \text { and } & \text { Zayd-NOM-INDEF }\end{array}$

'*None came to me and Zayd.'

While (17a) is a well-formed sentence, (17b) is both ungrammatical and meaningless. Furthermore, in (17a), the ExP 'illä zaydun cannot be considered as a ConjP simply because there are no two DPs or two CPs to be joined.

Third, ExPs can be fronted in some constructions (e.g., (4c) and (12a) above), but ConjPs cannot (everyone and John / * and John everyone). Fourth, while two conjunctions cannot co-occur together, that is, they cannot be adjacent, an exceptive particle can be adjacent to a conjunction to form one constituent that initiates a temporal adverbial clause (for more examples, see Ya'īsh, 2001:78-79):

\footnotetext{
${ }^{6}$ For ease of exposition, the conjunction phrases introduced by wa 'and' are compared with exceptive phrases with 'illā based on the assumption that other conjunctions like aw 'or', tumma 'then', lā 'not' have the same syntactic properties.
} 
18) a. ma ltaqi-tu-hu 'illā wa 'ajidu-hu yu-șali not meet-I-him except while I.find-him he-pray 'Whenever I meet him, I find him praying.'

$\begin{array}{lllll}\text { b. *ma } & \text { ltaqituhu } & \text { țumma } & \text { wa } \text { 'ajiduhu } & \text { yușali } \\ \text { not } & \text { meet-I-him then } & \text { while I.find-him } & \text { he-pray }\end{array}$

Fifth, conjunctions can join two full sentences, but exceptive particles cannot. Consider (19a,b).

19) a. 'abasa wa tawallā he.frowned and he.turned away

'He frowned and turned away.'

(Qur'ān, 80:1)

\section{b. *'abasa 'illā tawallā}

Sixth, in contrast with conjunctions, 'illa can have a clitic form of a pronoun attached to it as an ExP-complement, such as $-k \bar{a}$ 'you' in (20):

20) lam 'a'ud 'arā 'illā-kā

no longer see.I except-you

'I no longer see anyone except you.'

(Badawi, Carter, and Gully 2015:752)

Based on the given pieces of evidence related to the morphological and syntactic properties of exceptive particles and conjunctions, I argue that exceptive particles are not coordinating conjunctions; ExPs and ConjPs belong to two distinctive grammatical categories, and they serve entirely different grammatical functions. Arguments based on the differentiation between connected exceptives and free exceptives cannot account for the intricacies of exceptive constructions and their morphological and syntactic properties in Arabic (and maybe in other languages as well). Additionally, it is not clear in the literature why free exceptives 'select for a CP (CP2) whose head is null and is endowed with a feature that triggers and licenses ellipsis' (Pérez-Jiménez \& Moreno-Quibén, 2011:261). A curious reader may ask: why do not other coordinating conjunctions select for the same type of CP? What makes exceptive particles so unique? Are not constituents belonging to the same syntactic category supposed to be similar in their syntactic properties and distribution?

Nonetheless, the question now is: what is the categorial status of exceptive particles if they are not prepositions, adverbs or coordinating conjunctions? I claim that exceptive particles are functional heads generated in Ex. Ex stands for an exceptive or restrictive element that is used for specificatory, interpretational (i.e., inclusiveness vs. exclusiveness) functions. Ex merges with an $\mathrm{XP}$ to form an ExP (analogous to $\mathrm{C}$ that merges with a TP to form a $\mathrm{CP}$ in which $\mathrm{C}$ is the element that determines the force of the sentence). The projection of ExP is triggered by the existence of a feature carried by the exceptive particle 'illa that enables the particle to restrict the domain of qualification. This feature is [DS] (Domain Subtraction) that is used to subtract entities from the domain of a quantifier like every or no, and it is assumed in previous semantic studies (e.g., von Fintel, 1993) to exist in all exceptive phrases; thus, the existence of ExP as a phrase type different from PPs, AdvPs and ConjPs may be cross-linguistically valid.

To illustrate, in the ExP 'illa $+\mathrm{DP}$, the Ex-complement carries the valued [DS] feature as it denotes the entity excluded from the main clause and unvalued case feature. The particle 'illa has unvalued [u-DS] that is not determined in advance and needs to be valued by the Ex- 
complement DP via Agree, and it carries a valued accusative case [Acc-Case], as represented in (21):

21)

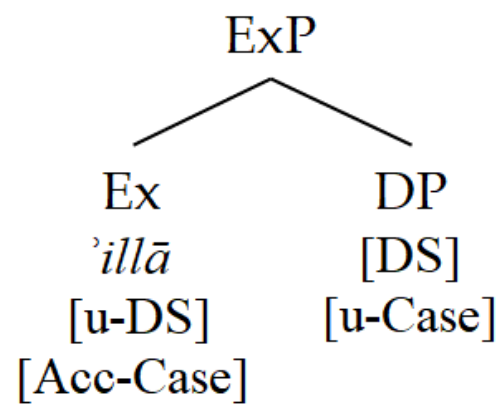

This representation explains the accusative case assignment on the Ex-complement only when the ExP is an adjunct, that is, it is not selected by one of the main clause constituents and does not affect theta or case assignment in the main clause (more details in section 4.3). As shown above, the ExP-complement is not always valued as accusative; it can have a particular case depending on its role in sentences lacking the ExP-associate or the same case as the Ex-associate in apposition constructions. In these structures, case alternation is triggered by the negative particle $m \bar{a}$ which is obligatorily present. As explained in section (4.1) and (4.2) below, the determiner $m \bar{a}$ deactivates the [Acc-Case] feature on Ex, and the Ex-complement has case via a process of feature percolation (e.g., Norris 2014; Winchester 2019) which allows for case feature to be spread from the D mā to its extended projection that includes the Ex-complement or both the Ex-complement and the Exassociate, as represented in $(22 \mathrm{a}, \mathrm{b})$, respectively. For simplification, let us assume the D mā which enters the derivation with [u-Case] has a nominative case (e.g., via Agree with T).

22) a.

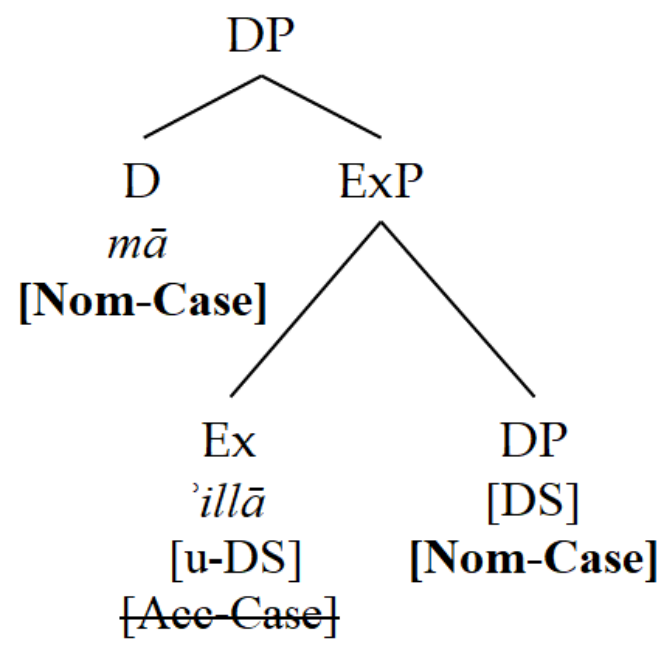

b.

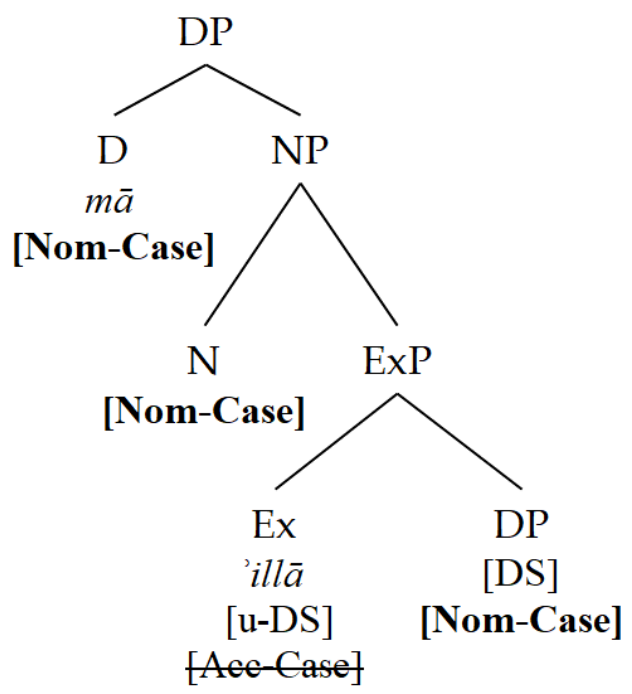

The puzzling case variation in some constructions but not others and the spread of a particular case is triggered by the ability of the particle $m \bar{a}$ to deactivate the [Acc-Case] on 'illä. This property of $m \bar{a}$ can be supported by other structures in which functional heads become inactive and ineffective when they are c-commanded by $m \bar{a}$ (called in the literature mā alkāfa 'suspending $m \bar{a}$ '). Supportive examples include case-assigning heads such as complementizers 
(e.g., 'inna, 'anna, ka 'nna, lakinna, and la 'lla), T associated with some verbs (e.g., țāla 'continue', katura 'abound', and qalla 'decrease'), and prepositional particles (e.g., rubba 'belike', ka- 'as', and $\min$ 'from') (for details and references, see, e.g., Abdullah 2019). To illustrate, the complementizer 'inna values the accusative case on the topic 'the believers' in (23a), but it becomes suspended or deactivated when c-commanded by $m \bar{a}$ in (23b). Notice the change of case endings on the DP following 'inna below.

23) a. 'inna al-ma'min-īna COMP DEF-believer-3MASC.PL.SBJ.ACC 'Surely, all believers are brethren.'

b. 'inna-mā al-ma'min-üna COMP-MĀ DEF-believer-3MASC.PL.SBJ.NOM 'Surely, all believers are but brethren.' ikwat-u-n brethren-NOM-INDEF

'ikwat-u-n brethren-NOM-INDEF

In addition to [Acc-Case] deactivation, the other feature on Ex, viz., [u-DS], is also affected due to the change of the semantics of 'illa $\bar{a}$. The $m \bar{a}$ combines with 'illa to create a discontinuous morpheme, more precisely, a focus particle that has an inclusive, rather than exclusive, interpretation; that is, while 'illa has the [DS] feature that codifies the exclusion of the referent (i.e., the Ex-complement) from the superset of entities denoted by the quantifier in the main clause, the $m \bar{a}$ - 'illa combination has the [DR] 'domain restriction' feature that codifies the inclusion of referent only, that is, $m \bar{a}$ - 'illa denotes a focused domain that includes only the ExP-complement to the exclusion of other alternatives or potentials. In this use, $m \bar{a}$ - illa forms one specificatory inclusive element similar perhaps to some pronouns in Tibeto-Burman languages (see Lustig 2010:304). In the light of these assumptions, ExPs selected by $m \bar{a}$ can be represented as follows:

24)

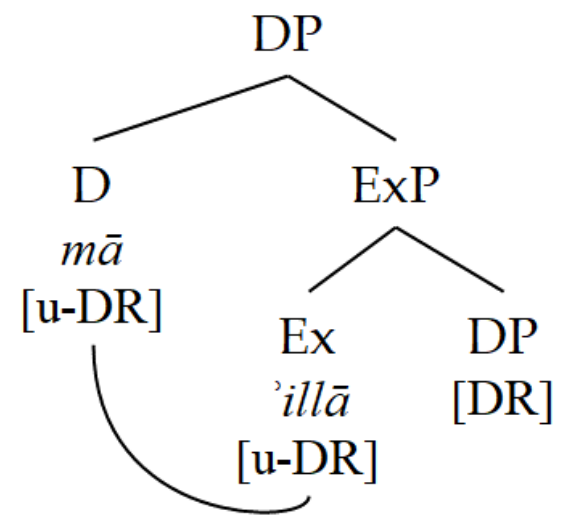

The curved line suggests that both $\mathrm{D} m \bar{a}$ and Ex 'illa form one discontinuous morpheme that has one unvalued domain restriction feature; consequently, both elements act as one probe that targets a goal with valued [DR] feature which is the ExP-complement that is determined in advance as a focused constituent. However, the given arguments claim a satisfactory account of ExPs in Arabic and help reconcile the debate in the literature concerning the nature of ExPs and their syntaxsemantic interface. The following sections claim a conceptually simpler and empirically more defensible analysis of ExPs. 


\section{Exceptive Phrases Revisited}

This section attempts to account for the syntactic properties of exceptive constructions in Arabic: (i) the suitability of an ExP to be used as an argument only in negative sentences lacking the ExPassociate; (ii) the optionality of the licensing DP (i.e., the ExP-associate) only in negative sentences; (iii) the correlation between the licensing DP and the type of sentence (i.e., affirmative and negative); (vi) the position of the ExP (i.e., at the right periphery of the clause or fronted) and inflectional morphology.

\subsection{ExPs with Argumental Function (ExPs in DPs)}

As indicated above, ExPs can be used as arguments only in negative sentences lacking the ExPassociate. The negation of the sentence is an essential condition that allows their use as DPs simply because they cannot be DPs in other structural environments. That is, ExPs can be DPs only when they are headed by a negative determiner equivalent to the English DP no one. To illustrate, let us begin with a discussion of English DPs as a start point for the analysis. According to Larson (2014:411-412), phrases like every one, all men, no one are DPs headed by a quantifier (i.e., every, all, no) in $\mathrm{D}$, thus a phrase like $l \bar{a}$ 'ahada 'no one' may have the representation below ${ }^{7}$.

25)

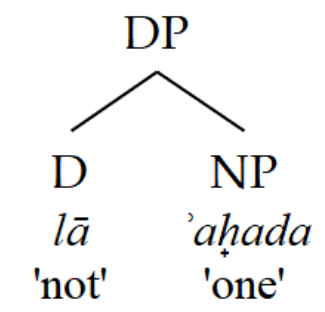

Phrases like more women than men and no one except Mary are DPs headed by comparatives (more) and quantifiers (no); thus, lā 'ahada 'illā zaydan 'no one except Zayd' can be represented in (19), bearing in mind that 'illā is not a preposition, and it forms an ExP rather than a PP:

26)

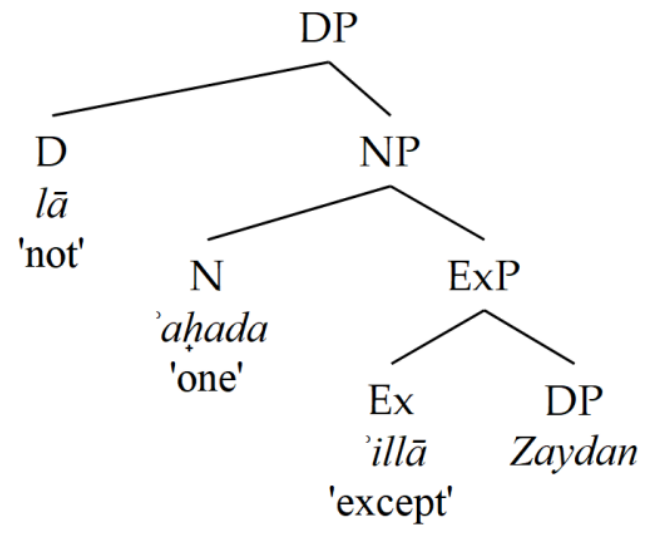

\footnotetext{
${ }^{7}$ Larson (2014) argues for the existence of a dP shell above DP (analogous to vP above VP), This argument is overlooked for ease of exposition (for a detailed analysis of the internal structure of Arabic DP, see AlBataineh and Branigan 2020)
} 
Furthermore, in the absence of an overt nominal like 'ahad 'one', the given phrase surfaces as $l \bar{a}$ 'illā zaydan 'no except Zayd' as in (27):

27)

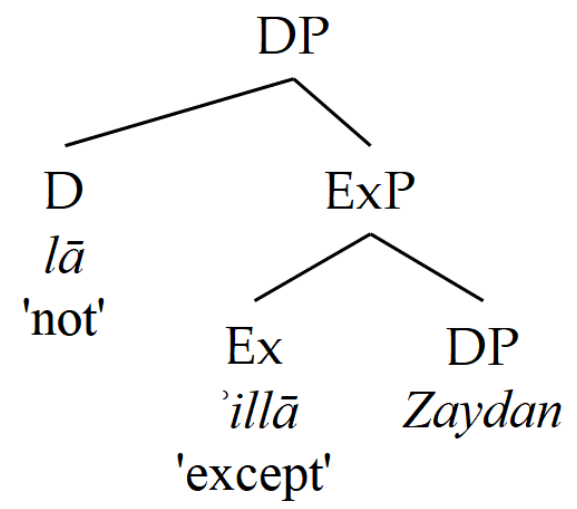

Roughly speaking, (27) is the structure of an ExP that functions as an argument of the verb. This view is based on several pieces of evidence that the negative particle is a determiner. Firstly, $l \bar{a}$ cannot merge with a nominal with an overt D. Notice that $l \bar{a}$ rajul 'no man' is well-formed, but *lä al-rajul 'no DEF-man' is ungrammatical because of the presence of D al-, and *lä rajul-u-n 'no man-NOM-INDEF' is also ill-formed because of the presence of nunation (i.e., the indefinite article). The ungrammaticality of forming $l \bar{a}$-DP stems from the fact that the overt nominal cannot be headed by two Ds $l \bar{a}$ and $a l$ or $-n$, bearing in mind that multiple or complex determiners in Arabic nominal projections are not allowed (cf. *al-rajul-u-n '*DEF-man-NOM-INDEF').

Secondly, when a DP headed by $l \bar{a}$ is c-commanded by a preposition, for example, the case feature on $\mathrm{D}$ is valued as genitive by the $\mathrm{P}$, as in (28):

Notice that when $l \bar{a}$ in $l \bar{a}$ damīr 'no conscience' moves to the bound preposition $b i$ - 'with' to form a complex preposition meaning 'without', the NP damīr surfaces with the D - $n$ as Last Resort in order to have the genitive case from the complex preposition based on the fact that in Arabic Ds are the only elements in the nominal projections that have [u-Case] that is valued from outside (cf. Ouhalla, 2013:329).

This point is supported by the third argument related to the adjacency condition on the ccommanding negative D. When $l \bar{a}$ is separated from the NP, i.e., when it moves to a higher position in the tree, the NP must have an indefinite article $-n$. Consider the obligatory absence of $-n$ in (29a) when $l \bar{a}$ is adjacent to it, and its obligatory presence in (29b) when $l \bar{a}$ is not adjacent.
a. $l \bar{a}$ rajul-a- $\left(*_{n}\right)$
fi al-bayt-i
no man-ACC- $(*$ INDEF) in
DEF-house-GEN

'No man in the house.'
b) $l \bar{a} f i$
al-bayt- $i$
rajul-u-*(n)
no in DEF-house-GEN
man-NOM-*(INDEF)

'No man in the house.' 
Returning to the analysis of ExPs, we see that the given assumptions account for the fact that an ExP consisting of 'illa and its complement cannot function as an argument except when it is headed by a negative determiner (e.g., la , $m \bar{a}$, lam, etc.,). Based on this understanding, we can see why only (30d) is ungrammatical:

30) a. $m \bar{a} \quad$ 'at $\bar{a}-n \bar{\imath} \quad$ 'illa $\quad z a y d-u-n$

not came-me except Zayd-NOM-INDEF

'None came to me except Zayd.'

b. $m \bar{a} \quad$ 'at $\bar{a}-n \bar{\imath} \quad$ zayd-u-n not came-me except Zayd-NOM-INDEF

'Zayd did not come to me.'

c. 'atā-nī zayd-u-n.

came-me Zayd-NOM-INDEF

'Zayd came to me.'

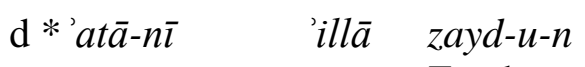

came-me except Zayd-NOM-INDEF

'*Except Zayd came to me.'

In (30a,b) $m \bar{a}$ 'illa zaydun and $m \bar{a}$ zaydun are DPs headed by the negative determiner $m \bar{a}$, and in (30c) Zaydun is also a DP headed by the indefinite article $-n$. The problem with (30d) is that the $\mathrm{DP}$ zaydun is headed by 'illa that forms an ExP, and ExPs cannot function as an argument simply because they lack the functional head that carries the [u-Case] through which the ExP-complement gets the case by percolation). The derivation of (30a) is illustrative (the tree is simplified by not showing the internal structure of the $\mathrm{V}^{\prime}$ ):

31)

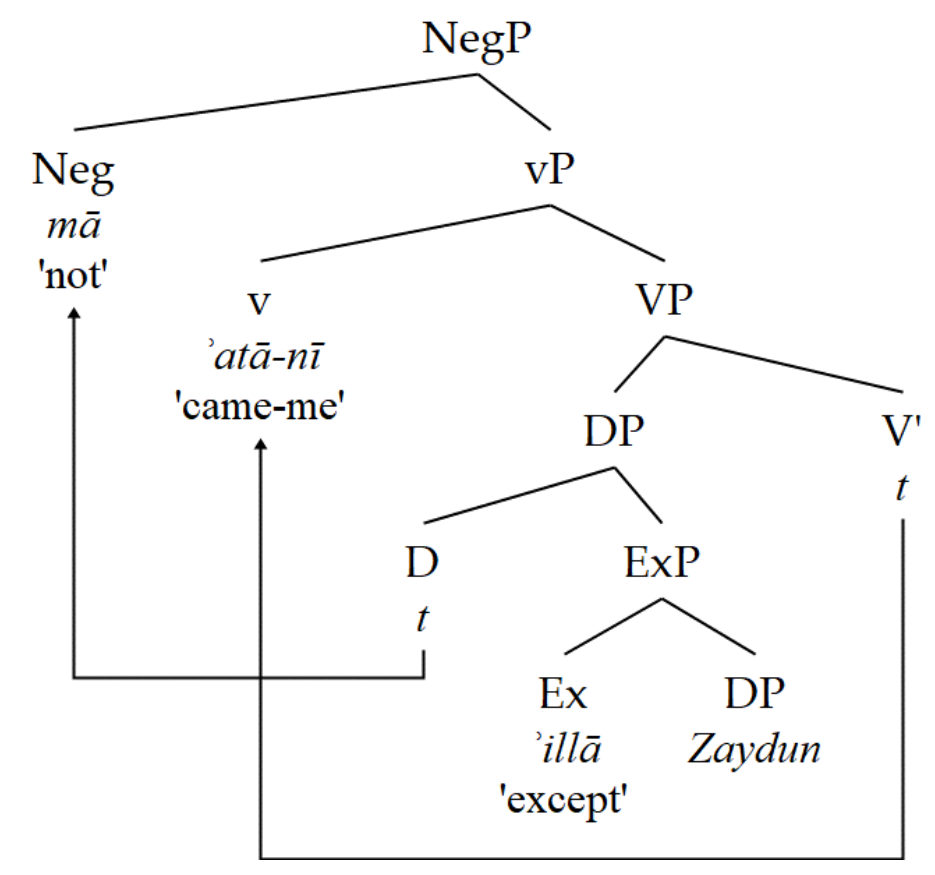


The DP zaydun merges with the exceptive particle 'illa to form ExP which in turn merges with the $\mathrm{D} m \bar{a}$ to form the DP $m \bar{a}$ 'illa zaydun. This DP merges with $\mathrm{V}$ ' (which is composed of the $\mathrm{V}$ 'ata 'come' and the DP - nī 'me' that attaches to $\mathrm{V}$ to form 'at $\bar{a}-n \bar{\imath}$ 'come-me') to form VP. Then, the VP merges with $\mathrm{v}$ (which triggers $\mathrm{V}$-to-v movement) to form $\mathrm{vP}$. The resulting $\mathrm{vP}$ merges with the functional head Neg to form NegP (for a detailed discussion of why NegPs occupy an intermediate position between vP and TP in a number of Arabic varieties, see Benmamoun, 2000). The Neg head attracts the negative element $m \bar{a}$ 'not' with the result of the surface order in (30a) in which $m \bar{a}$ precedes the verb.

As explained above, the $m \bar{a}$ deactivates [Acc-Case] feature on Ex 'illa and both $m \bar{a}$ and 'illa form one discontinuous element with [u-DR] 'domain restriction' feature that is valued by the DP zayd which carries a matching valued [DR] feature, consequently, a focused domain that includes only zayd to the exclusion of other alternatives is expressed in (32) below. Simultaneously, the $\mathrm{D} m \bar{a}$, which becomes nominative via feature valuation with $\mathrm{T}$, percolates [Nom-Case] (realized as $-u$ ) to the DP zayd (a red arrow represents case feature percolation).

32)

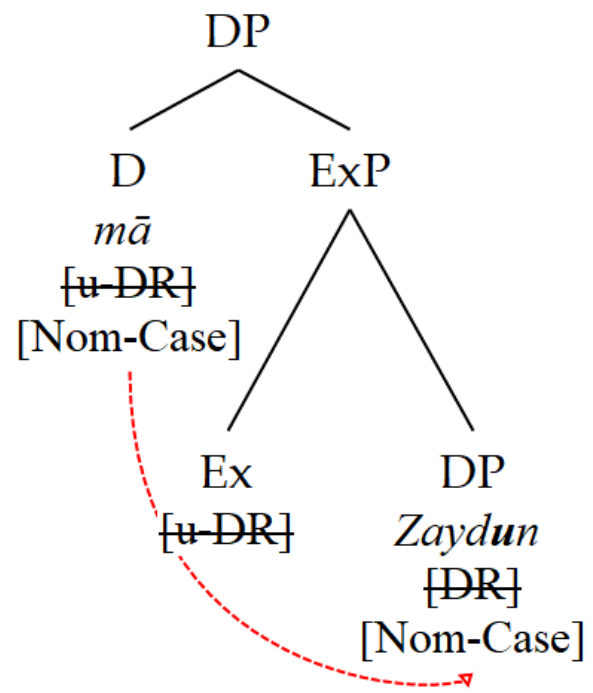

The given arguments find support in equivalent jumal 'ismiyyah 'nominal sentences' like (33) below. Consider how the DP rasūlun 'prophet' has the same behavior as zaydun in (30a-d):

33) a. mā Muhammad-u-n 'illā not Muhammad-NOM-INDEF except messenger-NOM-INDEF 'Muhammad is not but a messenger.'

b. $m \bar{a}$ Muhammad-u- $n$

rasūl $-u-n$

not Muhammad-NOM-INDEF messenger-NOM-INDEF

'Muhammad is not a messenger.'

c. Muhammad-u-n rasūl-u-n

Muhammad-NOM-INDEF messenger-NOM-INDEF

'Muhammad is a messenger.' 


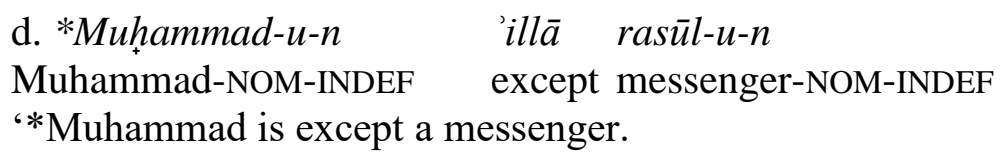

However, the use of negative exceptives as arguments is not a linguistic fact specific to Arabic; in many languages, parallel structures can be found with similar functions. Potsdam \& Polinsky (2017: 30-31) point out that in Tahitian (Polynesian) the exceptive phrase is composed of the negative element 'aita and the exceptive particle $r \bar{a}$ 'but, except.' Consider (34):

$\begin{array}{rllllllll}\text { 34) 'ua tae pauroamai te mau tamari'i'aita } & r \bar{a} & \text { 'o } & \text { Poe } \\ \text { PFV come all DIR DET PL } & \text { child NEG but }\end{array}$

'All the children came, only Poe didn't.'

Notice that in Tahitian, the ExP rā 'o Poe 'except Poe' is preceded by the negative element 'aita to form one meaning 'only Poe' equivalent to the Arabic DP $m \bar{a}$ 'illa zayd 'only Zayd.' Similar patterns also exist in other languages. Nevalainen (1999:167-168) states that in the Middle English "ne...but [occurs] in cases like Mary nis but a child "Mary is only a child' [... and the two elements ne...but undergo incorporation and become] nobbut in some northern varieties of British English". Hasegawa and Koenig (2011:1-3) notes that in Japanese "[the exceptive particle] -shika obligatorily co-occurs with the negative verbal suffix -na [which implies] morphosyntactic dependency between -shika and -na: -Shika requires the presence of -na" as exemplified in (35):

35) Yuna-shika ko-na-katta.

Yuna-SHIKA come-NEG-PAST

'Only Yuna came.'

What is remarkable about the given negative particles (i.e., Tahitian 'aita, Middle English $n e$, and Japanese $-n a$ ) is that they semantically rely on the exceptive particle to give the exclusive meaning, and they do not convey ordinary sentential negation. In a similar vein, Breitbarth (2015:13) points out that in Middle Dutch, Middle High German, and Middle Low German, the negative particle "nelen in exceptive clauses is not a negative marker with sentential scope" which suggests that both the negative particle together with the exceptive particle form an environment in which "the construction derives the exceptive semantics in a compositional fashion" which is parallel to Arabic DP $m \bar{a}$ 'illā zayd 'only Zayd'.

\subsection{ExPs in Badal 'Apposition' Constructions}

The previous subsection addresses the first point concerning the suitability of an ExP to be used as an argument only in negative sentences lacking the ExP-associate. The second point regarding the optionality of the licensing DP (the ExP-associate) reinforces the first point because the licensing DP can be omitted only in negative sentences, that is, what is optional is the overt nominal c-commanded by the negative element in D. To explain, let us consider (36a-d) which are identical to (30a-d) above except for the presence of an NP 'ahad 'one':
36)
a. $m \bar{a}$ 'atā-nì
'ahad-u-n
not came-me
one-NOM-INDEF
'None other came to me except Zayd.'
'illā zayd-u-n
except Zayd-NOM-INDEF

(Zabarah, 2017: 144) 


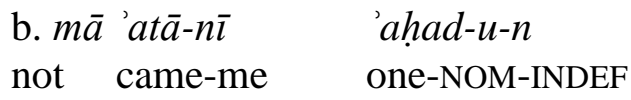

'No one came to me.'

c. 'atā-nī 'ahad-u-n

came-me one-NOM-INDEF

'Someone came to me.'

d. *'atā-nī 'ahad-u-n 'illā zayd-u-n

came-me one-NOM-INDEF except Zayd-NOM-INDEF

'*Someone came to me except Zayd.'

The parallel between (30a-d) and (36a-d) stems from the assumption that 'illa zaydun and 'ahadun 'illā zaydun cannot be used as DPs since both lack the D $m \bar{a}$. To illustrate, (36a) has the structure (37) below:

37)

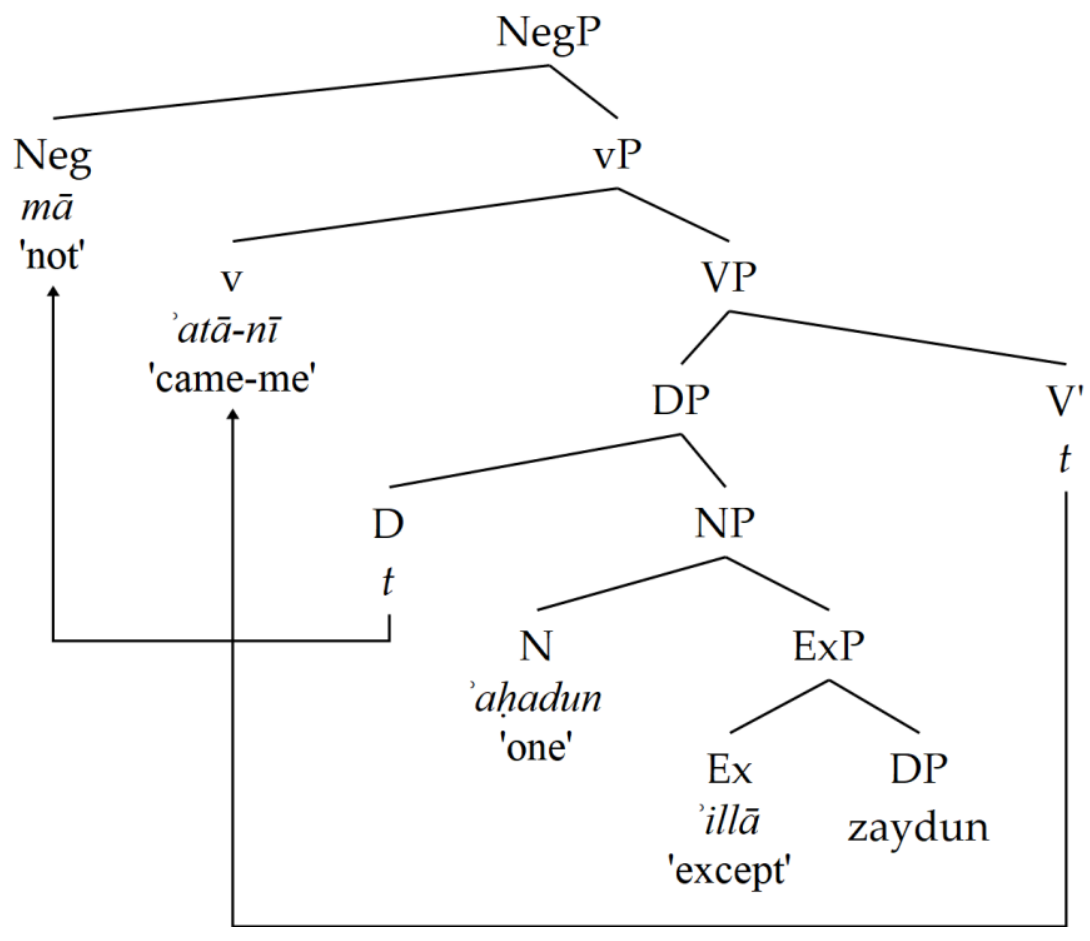

(37) is the same as (31) above except for the existence of an optional $\mathrm{N}$ 'ahad 'one' between the $\mathrm{D} m \bar{a}$ and the ExP 'illa zaydun. In other words, I claim that 'ahad 'one' is an optional $\mathrm{N}$ rather than a DP, and it is not the actual argument of the verb based on the fact that a preposition can precede it without affecting the grammaticality of the sentence. Consider (38):

38) $m \bar{a}$ 'atā-nì min 'ahad-i-n 'illā zayd-u-n

not came-me of one-GEN-INDEF except Zayd-NOM-INDEF

'None of them came to me except Zayd.'

(Zabarah, 2017: 146)

This argument is based on the simple fact that in Arabic the DP functioning as the argument of the verb cannot be preceded by a preposition. Consider the contrast in $(39 a, b)$ : 
39)
a. 'at $\bar{a}-n \bar{\imath}$
rajul-u-n
came-me
man-NOM-INDEF
'A man came to me.'
$\begin{array}{lll}\text { b. *'atā-n} \bar{\imath} & \text { min } & \text { rajul-i- } n \\ \text { came-me } & \text { from } & \text { man-GEN-INDEF }\end{array}$

(39a) is well-formed because rajulun is a DP that occupies the spec-vP; thus, it can be assigned the nominative case and the theta-role AGENT of 'atā 'come.' In (39b), rajul occupies the complement position of the preposition $\mathrm{min}$; therefore, it cannot be the agent of the verb. This is in contrast with (38) above since the presence of the same preposition does not lead to ungrammatically simply because 'ahadin is not a DP in the spec-vP position, rather it is an $\mathrm{N} \mathrm{c-}$ commanded by the negative element $\mathrm{D} m \bar{a}$.

Assuming the correctness of the given assumptions, I argue that ExPs in badal 'apposition' constructions are not in coordinating relation with the ExP-associate. The ExP and the ExPassociate are two constituents c-commanded by the negative D that projects into a DP. Previous studies arguing for coordination between the ExP-complement and the ExP-associate (i.e., studies adopting the 'connected exceptive' approach) may be misled by the inflectional morphology that is identical on the two. In (36a), for example, 'ahadun and zaydun have the same nominative ending $-u$ which shows that both constituents are two coordinated phrases similar to 'aḥmadun and zaydun in (40):

$\begin{array}{llll}\text { 40) 'atā- } n \bar{\imath} \quad \text { 'ahmad-u-n } & \text { wa } & \text { zayd-u- } n \\ \text { came-me Ahmad-NOM-INDEF } & \text { and } & \text { Zayd-NOM-INDEF } \\ \text { 'Ahmad and Zayd came to me.' } & & \end{array}$

There is no parallel between the conjunction phrase 'ahmadun wa zaydun and the NP 'ahadun 'illa zaydun because while the ConjP joins two independent DPs (i.e., the DP1 'ahmadun and the DP2 zaydun), the NP 'ahadun 'illa zaydun does not join two independent entities (i.e., two DPs); it refers to one entity, namely, 'someone except Zayd', and with the presence of the obligatory negation, the NP becomes a DP meaning 'no one except Zayd'= 'only Zayd'. As explained in the preceding subsection, $m \bar{a}$ and 'illa form one discontinuous morpheme that expresses a restrictive focus semantics; the focus particle adjoins to the DP zayd to create a restricted domain that includes only Zayd to the exclusion of other potentials. Such a claim, I argue, is cross-linguistically valid for the given syntactic and semantic reasons, and it is less plausible to parallel a ConjP with an ExP as they have two completely different syntactic computations and unrelated semantic interpretations.

Returning to the case morphology shared between 'ahadun and zaydun, I argue that the D $m \bar{a}$ which becomes nominative via valuation with T percolates [Nom-Case] (realized as $-u$ ) to both 'ahadun and zaydun. That is, $m \bar{a}$ hands over the nominative case feature to both nominals through a downward feature-percolation operation in the PF component, that is, the nominative case feature on $m \bar{a}$ is copied onto the c-commanded constituents 'ahadu $n$ which has a D - $n$ as a repair strategy (i.e., last resort operation triggered by the negative shift/ movement from D to $\mathrm{Neg}^{8}$ ) and zaydun

\footnotetext{
${ }^{8}$ Another alternative analysis is to assume that the negative particle stays in $\mathrm{D}$ and another identical particle is base-generated in spec-NegP. In this configuration, the $\mathrm{D} m \bar{a}$ gets null or $-n$ spellout by the haplology rule: an avoidance mechanism that eliminates/ modifies one of the two identical forms (e.g., phonemic, morphemic, or semantic haplological forms). This mechanism which is motivated by economy can also be
} 
in the same way that $\mathrm{C}$ percolates down phi-features onto $\mathrm{v}$ in a sentence like (41, taken from Radford, 2009:398), in which the bold-faced verbs appear in the plural rather than the singular form due to feature-percolation from $\mathrm{C}$ who:

41) Where are the boys [who Tom think [Dick believe [Harry expect to be late]]]

This argument stems from the simple fact that if we assume that 'ahadun and zaydun have the same case morphology by coordination, they are supposed to have the same case in all constructions. Such an assumption cannot hold because they may have different case endings, as the next subsection explains.

\subsection{ExPs as Separate Constructions}

As highlighted above, in some constructions, the ExP-complement does not share the same case as the ExP-associate, it may have an accusative case in structures where percolation cannot take place; that is, when the ExP-complement and the ExP-associate occupy two different positions in the tree (i.e., they do not form one DP, rather they are two separate phrases). Let us see what predictions we get from this claim. Consider case alternation in $(42 \mathrm{a}, \mathrm{b})$ :

42)

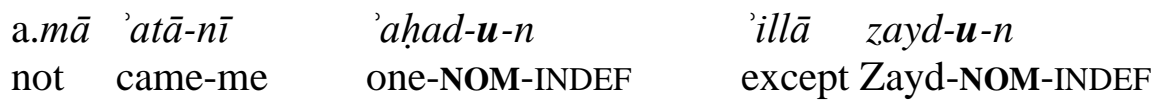

'None other came to me except Zayd.'

(Zabarah, 2017: 144)

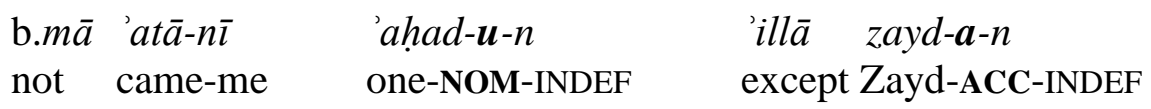

'None other came to me except Zayd.'

(Zabarah, 2017: 147)

In (42a), the nominative case on zaydun is accounted for in the light of the percolation hypothesis, but in (42b) the accusative case cannot be caused by the same mechanism because (i) the only

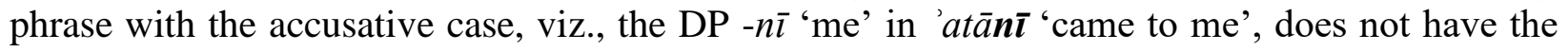
same thematic role like zayd, that is, the DP $-n \bar{l}$ has the theta-role THEME, but zayd is the agent of the verb (otherwise, we wrongly predict that in the sentence 'only Zayd came to me', 'me' refers to 'Zayd'; therefore the sentence means '*Zayd came to himself.'), and (ii) zayd cannot form one semantic and syntactic unit with the DP $-n \bar{\imath}$ in the same way it does with 'ahadun in (42a). Therefore, (42a) and (42b) have completely different structures. While 'ahadun and zaydun form one constituent (i.e., NP) in (42a), they do not in (42b). According to this understanding, the derivation of $(42 b)$ is the following:

43)

triggered in circumstances in which two forms have identical syntactic features (see, e.g., (Neeleman and Van de Koot 2006; Wong, Huang, and Chen 2018; Hiraiwa 2010; Al-Bataineh 2020a). 


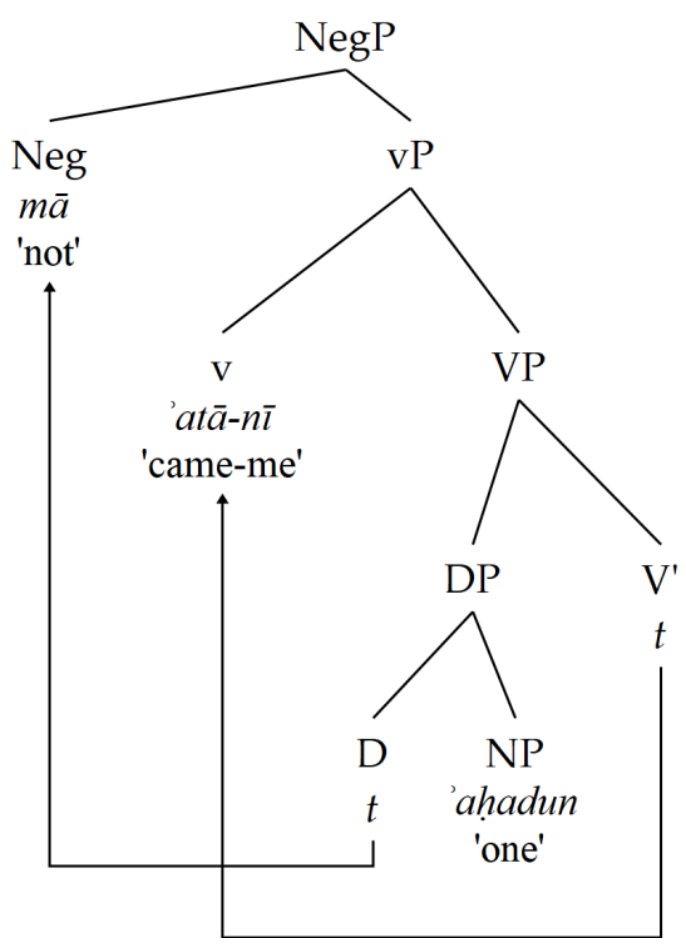

The $\mathrm{V}$ 'atā 'come' selects the DP - $n \bar{\imath}$ ' $m e^{\prime}$ ' (which due to its affixal nature, it attaches to $\mathrm{V}$ 'atā) to form the V' 'at $\bar{a}-n \bar{\imath}$. The V' merges with the DP $m \bar{a}$ 'ahadun 'no one' to form the VP which in turn merges with $\mathrm{v}$ that attracts $\mathrm{V}$ 'at $\bar{a}-n \bar{\imath}$. The resulting $\mathrm{vP}$ merges with the functional head $\mathrm{Neg}$ that attracts $m \bar{a}$ 'not' to form the NegP. This representation accounts for the main clausal structure before the merge of the ExP 'illa zaydan. I argue that the ExP is introduced into the structure at a later stage because its presence does not affect the case/ theta-role assignment and operations related to valuation and agreement. To illustrate, the ExP is assumed to be an adjunct that does not affect the syntax of the main clause. In Chomsky's (2004:117) words,

An adjunction construction is plainly not the projection of a head [...] if $\alpha$ is adjoined to $\beta$, the construction behaves as if $\alpha$ isn't there apart from semantic interpretation [...] $\beta$ retains all its properties, including its role in selection. There is no selectional relation between $\beta$ and $\alpha[\ldots]$ The adjunct $\alpha$ has no theta role in $\langle\alpha, \beta>$.

The adjunction of the ExP is not selected by the DP $-n \bar{l}$ ' $m e$ ' and does not affect theta role or case assignment of the DP - $n \bar{l}$, that is because, according to Chomsky (2004:117), it is formed by pair Merge, rather than the familiar set Merge. Unlike the symmetrical set Merge that yields syntactic objects that are free binary sets, pair Merge is an asymmetric operation that forms an ordered pair $<\alpha, \beta>$ by the attachment of $\alpha$ to $\beta$ on a separate plane (for a similar view, see Lebeaux, 1991, cited in Fukui \& Narita, 2014:20). The adjunction of the ExP (i.e., by the operation of pair Merge), as indicated by Chomsky (2004:118), exists at the SEM interface because 'richness of expressive power requires an operation of predicate composition: that is not provided by set Merge' ${ }^{9}$. Assuming the correctness of these claims, the adjunction of the ExP 'illa zaydan can be

${ }^{9}$ Although Sportiche (2019:416) admits that Late Merge has been successfully utilized in many influential studies as "its logic remains" regardless of the particulars, she criticizes the operation as it yields 
represented in (44b). Notice that ExP does not affect the main constituents of the VP shown in (44a):

44) a.

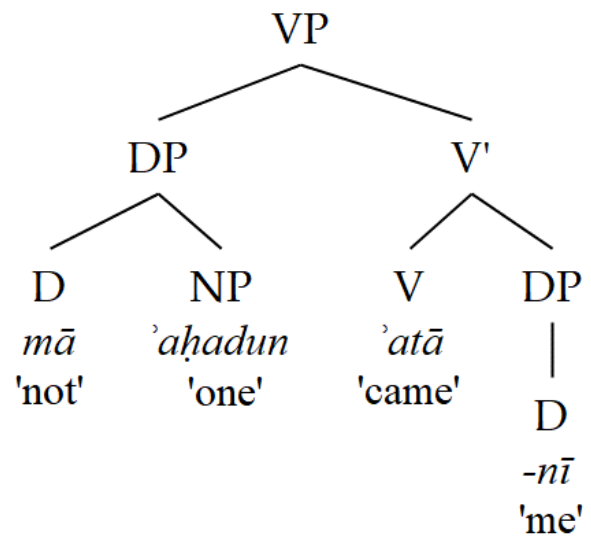

b.

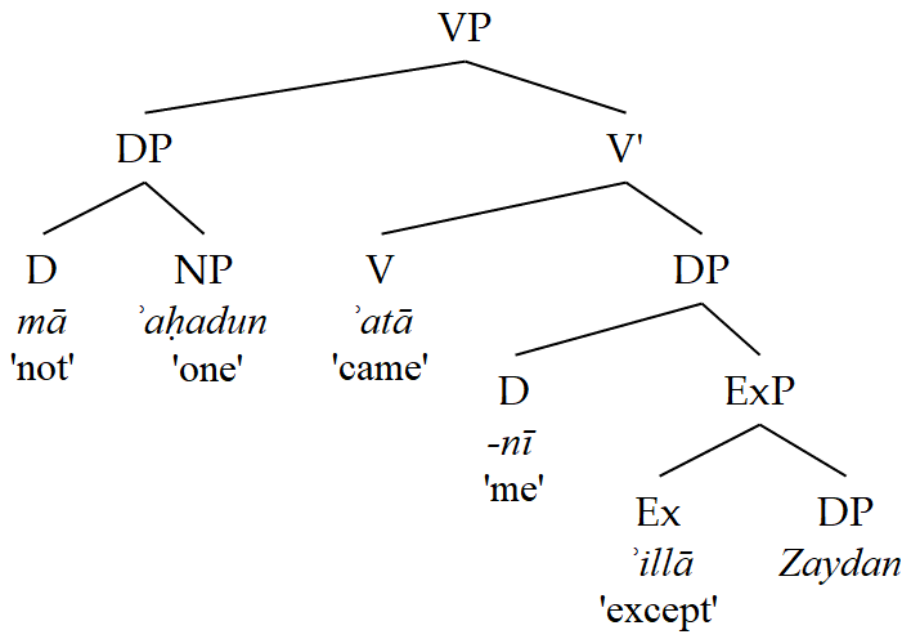

The adjunction of the ExP at a later stage of the derivation can be supported not only by case alternation and the absence of any effect on the theta-role assignment as discussed above but also by other arguments as well. Firstly, the ExP is phonologically separated from the main clause, that is, it forms an independent unit due to the boundary created by a prolonged pause preceding it. According to Moutaouakil (2009:89), in constructions with case marking distinctions, the ExP 'stands at the phonological level of organization as an autonomous intonational unit [separated from] the preceding intonational phrase [by a pause]'. Secondly, the Exp is not restricted to a specific position in the sentence; it can be in a lower position or fronted as $(45 \mathrm{~b}, \mathrm{c})$ demonstrate:

45)

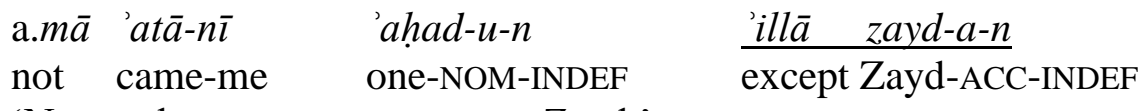

'None other came to me except Zayd.'

b. $m \bar{a}$ 'atānī, 'illā zaydan, 'ahadun

\section{c. 'illā zaydan, mà 'atānì 'ahadun}

The different positions of the ExP 'illa zaydan indicate that it is not selected by one of the syntactic objects of the clause, that is, it is not introduced to the clause by set Merge operation, instead by late Merge as evidenced by the absence of any effect on the semantic content of the

countercyclicity and argues for another approach, viz., Neglect; a mechanism by which portions of structures can be totally or partially ignored at the interfaces. Another proposal, viz., top-down derivational model, is proposed by Bruening and Al Khalaf (2019). However, these alternative approaches seem either too permissive or speculative and inadequate to capture facts of Arabic exceptives; hence, drawing on Haddad's (2019) arguments for counter-cyclic merge as a Last Resort for adjuncts in Levantine Arabic, I maintain that Late Merge is more plausible for the present study because, as highlighted by Chomsky, Gallego, and Ott (2019:249) adjuncts and parenthetical expressions "are generated independently and interpolated or juxtaposed only in production". 
main clause $m \bar{a}$ 'atān $\bar{l}$ 'ahadun 'no one came to me'. Thirdly, as highlighted by the reviewer, the exceptive phrase 'illa zaydan can be separated from the main clausal structure by an intervening element such as an adverb (e.g., amsi 'yesterday') or, as in (46), by a parenthetical clause without any effect on the well-formedness of the sentence.

46) là talbs-u

not wear.3SG.FEM.SBJ

'illā marrat-a-n

al-fustān-a, mahmō kāna $\dot{g} \bar{a} l y-a-n$,

except

single-ACC-INDEF

DEF-dress-ACC regardless

was

expensive-ACC-INDEF

wāhidat-a-n

'She wears the dress, no matter how expensive it was, only one single time.'

(Badawi, Carter, and Gully 2015:752)

Fourthly, while in negative sentences discussed above the ExP-complement may share the same case via percolation from the c-commanding D $m \bar{a}$ or the accusative case via Agree with the exceptive particle 'illā, in affirmative sentences percolation does not take place, and the ExPcomplement is assigned only the accusative case, consider (47):

47)
a. 'at $\bar{a}-n \bar{\imath} \quad a l-q a w m-u$
'illā 'ab- $\overline{\boldsymbol{a}}-k a$
came-me
DEF- people-NOM
except father-ACC-your

'People came to me except for your father.'

(Zabarah, 2017: 147)
b. *'atā-nī al-qawm-u
'illā 'ab- $\overline{\boldsymbol{u}}-k a$
came-me DEF- people-NOM
except father-NOM-your

In contrast with (47a), (47b) is ungrammatical because the DP ' $a b$ 'father' is marked nominative which is not allowed due to the impossibility of case percolation in affirmative sentences. In (47b), the case feature on the NP qawm 'people' cannot be handed over to ' $a b$ 'father' since they cannot form one phrase. Based on these assumptions, ExP-complement ' $a b$ 'father' has only the accusative case that is valued via Agree with the exceptive particle, as shown in $(48 \mathrm{a}, \mathrm{b})$ :

48) a.

b.
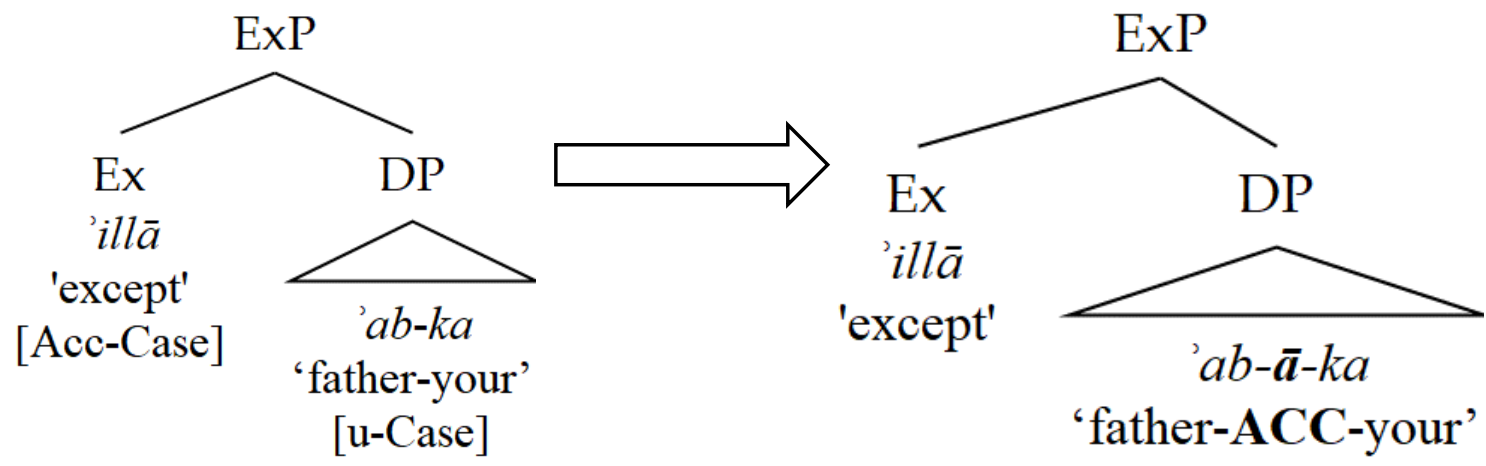

These representations imply that all syntactic operations related to the main clause 'atāni alqawmu 'people came to me' take place before the merge of the ExP 'illā 'abāka 'except your father' in which the DP 'abāka is affected only by the functional head 'illā that carries [Acc-Case] feature. However, the given arguments are not specific to Standard Arabic varieties, Khalaily (2019) provides several pieces of evidence for the adjuncthood of ExPs in Palestinian Arabic. However, 
I argue that case alternation in negative sentences and the assignment of one and only one case in affirmative sentences cannot be accounted for in the light of previous proposals in the literature that exceptive particles are coordinating conjunctions that form ConjPs.

\subsection{ExPs and Case Assignment}

The discussion so far shows that the ExP can occupy distinct positions in the sentence. These positions can be subcategorized under three main groups. The first group involves ExPs functioning as arguments when they are c-commanded by a negative determiner like $m \bar{a}$ which percolates the case feature to the excepted nominal. The second group includes ExPs in badal 'apposition' constructions. In this group, the ExP is syntactically parallel to the one in the first group in the sense that it is dominated and c-commanded by a negative determiner that hands overs the case feature, and in both groups, the negative particle is the landing site for case valuation. The third group includes ExPs as separate constructions (i.e., adjuncts); that is, they are not selected by the negative D or any constituent in the main clause; consequently, the case feature of the ExPcomplement is valued as accusative via Agree with the Ex 'illā. Claims about the adjunctive ExPs beg two questions; how can the exceptive particle be a functional head with a valued case feature? and why is the ExP-complement valued as accusative, rather than nominative or genitive?

Based on several pieces of evidence and tests, I argue that 'illa is a functional head that carries a case feature. First, 'illa is a functional head because it belongs to the closed class of function words; it resembles, for example, a preposition like min 'from' as both are limited in number. In Arabic, exceptive particles include 'illa, xala, 'ada, h̆ǎ̌a, and siwa. Crosslinguistically, equivalent particles are also limited, compare for example, ne...que, sauf, and excepté in French, excepto, salvo and menos in Spanish, except and but in English, 'aita rā and noa 'aita in Tahitian. Second, the properties of 'illā determine the properties of its projection (i.e., ExP), that is to say, in 'illa + DP (e.g., zaydan), the DP is a maximal projection of D and cannot project further, and in the specifier position, 'illa merges to form a maximal projection that is determined by its properties (analogous to the fact that a CP is interpreted as interrogative or declarative depending on the properties of C (i.e., [+wh] or [-wh]). Third, following Bittner \& Hale (1996:4), I assume that if exceptive particles are functional heads, they are supposed to 'exhibit canonical headlike behavior, given the appropriate morphosyntactic condition'. That is, they are expected to be in the initial position in head-initial languages, and this is exactly the situation in Arabic, French, English, Spanish, etc. Fourth, a head values case to an argument, 'if the structural relation between the two satisfies the relevant licensing condition' Bittner \& Hale (1996:6). The structural relation between 'illa (as the case valuer) and its complement (i.e., the following DP) is licensed by the syntactic relations (i.e., selection and agreement) that enable their combination. The combination of the DP with 'illa is licensed by the selectional features of the latter that require specific types of complements. Consider the ungrammaticality of (49) below.

$\begin{array}{lll}\text { 49) } & \text { mā } \quad \text { zayd-u-n 'illa } & \text { qāma } \\ \text { not } & \text { Zayd-NOM-INDEF } \quad \text { except } & \text { stand } \\ \text { '*Zayd is nothing except stood.' } & \end{array}$

(Ya'īsh, 2001:79)

(49) is ungrammatical because the selectional requirements of 'illa are not met. The exceptive particle does not select a finite verb phrase not only in Arabic or French (O'Neill, 2014:177) but 
also in other languages (e.g., Spanish, English, Romanian, Hebrew, etc.,) as well ${ }^{10}$. Based on these selectional properties, I assume that 'illā values [u-Case] of its complement (and not vice versa).

In addition to the given arguments, I consider two syntactic tests, namely, obligatory adjacency and c-command of the ExP-complement. Concerning the first test, strict adjacency is required between 'illa and its complement, that is, there must be no constituent intervening between the head and its complement (cf., e.g., 'illa $*$ gadan 'tomorrow' zaydan). The obligatory adjacency of 'illa to zaydan constitutes a strong argument for the constituency of the string 'illa zaydan since the intervening constituent prevents the operation of case valuation to apply between 'illa and zayd. Regarding the second test, I find that in all constructions in Arabic and other languages, the exceptive particle c-commands the DP, that is, 'illa must precede the excepted nominal, and it is ungrammatical to have a structure like *zaydan 'illa.

The second question raised above is why the excepted noun is valued as accusative rather than nominative or genitive. This question cannot be answered in the light of previous analyses in the literature considering exceptive particles as prepositions, adverbs or coordinating conjunctions simply because all these syntactic categories cannot value accusative case in Arabic. Therefore, I find it more convenient and plausible to suggest, following traditional Arabic grammarians (e.g., Ya' ish, 2001:47), that the accusative case is the only possible case to be valued due to the existence of an invisible verb 'astațī 'exclude.1SG.SBJ' that is suppressed and replaced by 'illā ${ }^{11}$. To illustrate, the DP is marked accusative because it is regarded as an object of the deleted verb 'astațī 'exclude.1SG.SBJ'. Accordingly, the underlying structure of 'illa zaydan is (50) in which 'illa is a substitute for the verb, and zaydan is the direct object:

50)

$$
\begin{array}{ll}
\text { 'illā zaydan }=\text { 'astatn̄ } & z a y d-a-n \\
\text { except Zaydan= exclude.1SG.SBJ } & \text { Zayd-ACC-INDEF }
\end{array}
$$

Based on this assumption, I argue that 'illā carries a valued [ACC-Case] feature, and the DP is valued accusative via Agree with 'illā. This analysis is in contrast with Badawi, Carter, and Gully's (2015:784) claim that 'illa is etymologically 'in 'if' and $l \bar{a}$ 'not'. I argue that this claim seems implausible because the two elements 'in 'if' and $l \bar{a}$ 'not' are semantically and syntactically different from the exceptive particle, and their combination cannot yield the semantics or the syntax of 'illā. From a semantic perspective, 'in 'if' and $l \bar{a}$ 'not' denote a conditional particle meaning 'if not', and that is not related to 'except'. Syntactically, 'in 'if' and $l \bar{a}$ 'not' have different selectional properties than the exceptive particle. 'in 'if' is a conditional particle which must select a finite verb (Ya' $1 \bar{s}$ sh 2001:120), and $l \bar{a}$ 'not' is a negative particle that does not syntactically affect the complement, as exemplified in $(51 \mathrm{a}, \mathrm{b})$. In contrast, the exceptive particle cannot select a finite verb, as demonstrated in (52):
51) a. 'in tadrus
tanjah
if study.2SG.SBJ.MASC succeed.2SG.SBJ.MASC
'If you study, you pass.'

\footnotetext{
${ }^{10}$ I did not find one counterexample to this statement. However, this claim is based on the studies I am familiar with, and since exceptive constructions are relatively poorly studied, further future research is needed to verify this claim.

${ }^{11}$ Vocative particles like $y \bar{a}$ in $y \bar{a}$ rajulan 'O man' are analyzed in a similar vein; the vocative $y \bar{a}$ is argued to be a substitute of a deleted verb ' $a d$ ' $\bar{u}$ 'call.1SG.SBJ' (for details, see Al-Bataineh 2020b).
} 
b. 'illā tanșurūhu faqad nașarahu Allahu

'in-lā tanșur- $\bar{u}-h u \quad$ fa-qad nașara-hu allah-u

if-not support-2PL.SBJ.MASC-him then-certainly supported-him Allah-NOM

'If you do not aid him [the Prophet], Allah has already aided him.' (Qur'ān, 9:40)

52) fa'ala zayd-u-n kall-a šay'-i-n 'illa *darasa

did Zayd-NOM-INDEF every-ACC thing-GEN-INDEF except studied

'*Zayd did everything except studied.'

Moreover, in contrast with conditional 'illa 'if not', exceptive 'illā can be followed by a conditional particle such as 'i $\underline{d} \bar{a}$ 'if', as in (53):

$\begin{array}{llll}\text { 53) lā 'atakalamu 'illa 'idāa } & \text { samah-ta } l-\bar{l} \\ \text { not } & \text { speak.1SG.SBJ except if } & \text { allowed-you } & \text { to-me }\end{array}$

'I do not speak except if/when you allowed me to do so.'

In brief, exceptive 'illa is not a combination of the two particles 'in 'if' and $l \bar{a}$ 'not', and exceptive structures are completely distinct from conditional ones which have different syntax (for an overview, see, e.g., Badawi, Carter, and Gully 2015:709-747; Ryding 2005:671-676; Alhawary 2011:297-305). Another alternative assumption is that 'illä is a combination of the complementizer 'inna and the conjunction $l \bar{a}$ 'not'. This assumption also seems implausible because the complementizer 'inna requires a full TP as its complement, and this requirement cannot be satisfied in the given examples above because the Ex-complement is a DP, not a TP. Moreover, the conjunction $l \bar{a}$ 'not' conjoins two constituents of matching syntactic status such as two DPs in (54).

54)
qama zayd-u-n
là $\quad k a ̄ l i d-u-n$
stood Zayd-NOM-INDEF
not Khalid-NOM-INDEF
'Zayd stood, not Khalid.'

This requirement cannot be met in constructions (discussed in section 4.1 above) in which the Exassociate is absent. Consider the equivalent of (54) below and notice how the absence of the Exassociate zaydun requires the negative particle $m \bar{a}$ and leads to an inevitable change in meaning.

55) *(mā) qama 'illā kālid-u-n

not stood except Khalid-NOM-INDEF

'Only Khalid stood.'

This indicates that neither the complementizer not the conjunction can be the components of 'illa (see, e.g., Ibn Ya'īsh 2001:87; Al'Anbārī 1982:264-265, for more supportive arguments), and a more plausible view is to assume that 'illā is a single particle which substitutes and replaces the verb 'exclude', and this explains why the complement of 'illa can be any maximal projection except a finite VP.

\section{Other types of ExP-complements}

In the preceding sections, the exceptive constructions include a DP as the Ex-complement, and this type of structure, called 'connected exceptives' in the literature, is different from 'free exceptives' which include any maximal projection as an Ex-complement (e.g., Hoeksema 1995; Soltan 2016; Pérez-Jiménez and Moreno-Quibén 2012). While in connected exceptives only 
nominal constituents can follow the exceptive particle, in free exceptives any XP-level constituent can follow the exceptive marker heading the construction, such as prepositional phrases, adverbial phrases, or even full clauses, as exemplified in (56a-c), respectively, but not finite verb phrases (as exemplified in (46) and (52) above).

56) a. hadihi al-furșat-u lā najidu-hā 'illā fì-l-qāhirat-i this.FEM.SG DEF-opportunity-NOM not find.we-it except in-DEF-Cairo-GEN 'We do not find this opportunity except in Cairo.'

(Ryding 2005:652)

$\begin{array}{lll}\text { b. } m \bar{a} j \bar{a}{ }^{\prime} a & \text { zayd-u-n } & \text { illā } \quad \text { dăhik-a-n } \\ \text { not came } & \text { Zayd-NOM-INDEF } & \text { except laughing-ACC-INDEF } \\ \text { 'Zayd has never come except laughing.' }\end{array}$

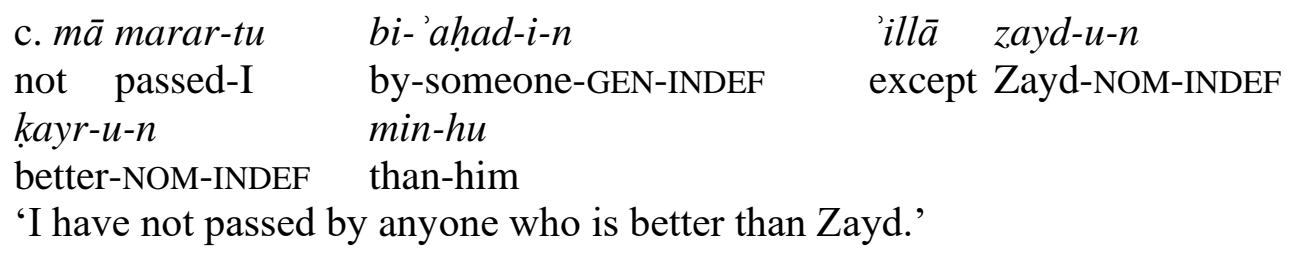

Contra previous studies (e.g., Pérez-Jiménez and Moreno-Quibén 2012; Soltan 2016; among others), three points should be highlighted in (56a-c). First, free exceptives cannot include any maximal projection, as exemplified in (46) and (52) above, the Ex-complement cannot be a finite VP for the simple reason that 'illa is a substitution of the verb 'exclude' which cannot select a finite verb as its complement (a phenomenon that applies to other languages such as English and French as well (see, e.g., O’Neill 2011:177)). Second, free exceptives cannot 'have a greater distributional freedom' than connected exceptives (Pérez-Jiménez and Moreno-Quibén 2012:583). While connected adjunctive ExPs can be fronted, free connectives cannot. Notice that fronting the ExPs in (56a-c) above results in ungrammaticality:

57) a. *'illā fìlqāhirati, hadihi alfurșatu lā najiduhā

b. *'illā dāhhikan, mājā' a zaydun

c. *'illä zaydun kayrun minhu, mā marartu bi'ahadin

Third, the main difference between connected exceptives and free exceptives is not primarily related to the type of constituent (i.e., DP vs., any XP), rather in the presence of the negative element. While in connected exceptives the negative element can be optional as evidenced in the grammaticality of ExPs in affirmative sentences, in free exceptives the negative element is always obligatory. The absence of $l \bar{a}$ 'not' in (56a) and $m \bar{a}$ 'not' in $(56 \mathrm{~b}, \mathrm{c})$ makes the aforementioned sentences ill-formed.

Previous studies (e.g., Hoeksema 1995; Harris 1982; Pérez-Jiménez and Moreno-Quibén 2012; Soltan 2016; among others) claim that the different types of ExP-complements support the analysis of free exceptives as conjunction constructions in which Ex-complements are the remnants of an elliptical sentence. In Pérez-Jiménez and Moreno-Quibén's (2012:591) words,

the exceptive conjunction selects for a $\mathrm{CP}$ whose head is null and is endowed with a feature that triggers and licenses the ellipsis process (the E-feature). This feature, on the one hand, attracts one or more constituents internal to $\mathrm{CP} 2 \ldots$ to the left periphery of the elliptical 
sentence; these constituents are thus the remnants of the ellipsis process. On the other hand, the E-feature on $\mathrm{C}$ also forces the deletion/non-pronunciation of the phonological features of the syntactic complement of $\mathrm{C}$.

For reasons given in section (3) above, the exceptive particle 'illa cannot be analyzed as a coordinating conjunction. Following the same line of thought, the paper argues that not only in connected exceptives but also in free exceptives, 'illā is not a conjunction but a functional head that selects a DP or any XP (except a finite VP) as its complement. The aforementioned arguments of the E-feature in $\mathrm{C}$ that triggers the movement of some constituents and deletion of the remaining ones in CP2 seem unmotivated and implausible for several reasons. First, this feature does not exist in clauses selected by coordinating conjunctions such as $w a$ 'and' as evidenced in the replacement of 'illa with any conjunction results in ungrammaticality of sentences (56a-c) because the conjunction conjoins two unparallel constituents. Second, it is not clear why any XP can be the remnant of the elliptical sentence but not a finite VP even though two finite VPs can be coordinated in Arabic and other languages. Third, it is mysterious when and under which conditions the claimed E-feature applies, that is, it is not clear why the E-feature triggers movement and ellipsis in some, but not all, constructions. Notice that the Ex-complement can be a full clause in some constructions, and no movement or deletion takes place. The existence of this feature becomes more questionable and implausible in cases where ellipsis results in ungrammaticality of structures like (56c), as exemplified in (58a-c).

58)

$\begin{array}{lll}\text { a. } m \bar{a} \text { marar-tu } & b i \text {-'ahad-i-n } & \text { 'illa } \quad z a y d-u-n \\ \text { not passed-I } & \text { by-someone-GEN-INDEF } & \text { except Zayd-NOM-INDEF }\end{array}$
kayr-u-n min-hu NOM-INDEF better-than-him 'I have not passed by anyone who is better than Zayd.'
b. ${ }^{*} m \bar{a}$
marar-tu
bi- 'ahad-i-n
not passed-I by-someone-GEN-INDEF
not passed-I by-someone-GEN-INDEF
'illā zayd-u-n
except Zayd-NOM-INDEF

'*I have not passed by anyone except Zayd.' (intended: Zayd is the subject of the elliptical sentence)

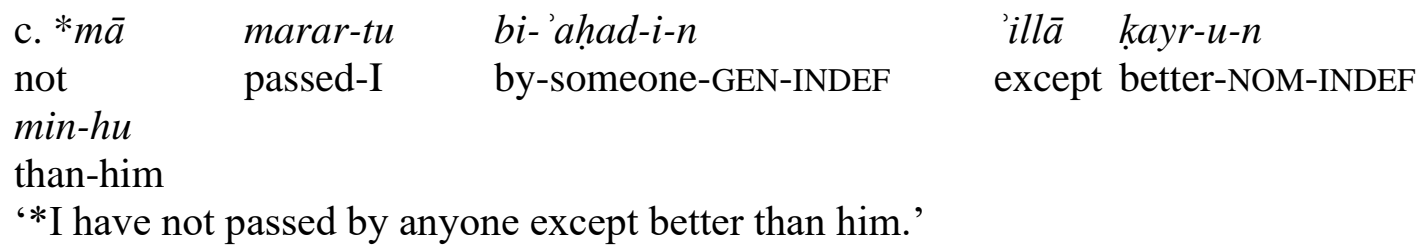

While a full clause can be the Ex-complement in (58a), deletion of one of its main components results in ungrammaticality. Notice that for (58b) to be well-formed, zayd must be valued as genitive and must be preceded with a preposition because it is in an appositional relation with 'ahad-i-n 'someone-GEN-INDEF'.

Based on these arguments, the paper maintains that 'illā is a functional head that selects any XP other than a finite VP, and by Occam's razor, there is no linguistic need for the E-feature in $\mathrm{C}$ that triggers movement and ellipsis, as such operations are not required even in cases where Ex-complements are nonsententials fragments such as (59). 
59)
kull-u
aț-ṭullāb-i
yadrus-üna
fi-l-maktabat- $i$
'illā
all-NOM
DEF-students-GEN
study-3PL.SBJ.MASC
in-DEF-library-GEN
except
zayd-u- $n$
fi-l-bayt-i
Zayd-NOM-INDEF in-DEF-house-GEN
'All students study in the library except Zayd in the house.'

The verb 'study' missing in the Ex-complement 'Zayd in the house' is not necessarily elided simply because there is no evidence that it originally exists in the Ex-complement. In other words, 'Zayd in the house' is a small clause that lacks a verb (i.e., a non-TP constituent), and the derivation of the ExP can be represented as follows [Ex 'illā [sc [DP zaydun] [PP filbayti]]]. Ellipsis hypothesis that claims the possibility of deleting the verb 'study' and leaving behind its complement 'in the house' wrongly predicts that heads can be elided without their complements and, following the same misleading logic, the preposition fi- 'in' can be wrongly predicted to be elided in (59) (*'illa zaydun fi-lbayti 'except Zayd in the house'), contra to fact. Arguing that 'illā selects a small clause in (59) rather than a full $\mathrm{CP}$ involving processes of movement and deletion is more plausible and economical (for a similar view of English exceptives, see, e.g., Moltmann 1992; and for detailed analysis of SCs in Arabic, see Al-Bataineh 2020a; Al-Bataineh and Branigan 2020). In brief, 'illa is not a coordinating conjunction in both connected exceptives and free exceptives, and it selects a base-generated XP that does not undergo deletion or ellipsis.

\section{Conclusion}

This paper explores the syntax of Arabic exceptive constructions which involve an intricate interaction among negation, word order, and case marking. Based on the semantic and structural differences of ExPs, some syntactic restrictions are imposed on their argumental function, the optionality of their associates, and the inflectional morphology of their complements. The paper shows that negation is an essential condition for the suitability of an ExP to be used as an argument and for the optionality of the licensing DP (i.e., the ExP-associate). The inflectional morphology of the ExP-complement seems to be influenced by negation and correlated with the position of the ExP (i.e., at the right periphery or fronted). Based on this overview, the paper argues against the analysis of the exceptive 'illa as a preposition, an adverb, or a coordinating conjunction. A more plausible assumption is that 'illa is simply explanatory element used for specificatory, interpretational (i.e., inclusiveness vs. exclusiveness) functions.

Regarding the correlation between the position of 'illā and case valuation, the paper argues that only when ExPs are argumental or appositional, 'illa is selected and c-commanded by a negative determiner that deactivates or suspends the case feature of 'illa, and the combination of the negative determiner and the exceptive particle form a discontinuous morpheme with the [DR] feature that codifies the inclusion of referent only to the exclusion of other alternatives, that is, they denote a focused domain. When the ExP is an adjunct, 'illa is not selected by a negative D or any other constituent, therefore, the [Acc-Case] and [u-DS] features on 'illa are active and the valuation operation takes place with the result that the ExP-complement is valued accusative and is interpreted as excluded from the domain of a quantifier in the main clause. Moreover, based on several arguments, the paper maintains that 'illa is a functional head that carries only the accusative case because it is a substitute of an invisible verb 'exclude' that is suppressed and replaced by the exceptive particle. 


\section{References}

Abdullah, Fatimah. 2019. "'ațr attarkīb atțāri' 'alā alkalma biduḳū mā alkāfa." Journal of Education College Wasit University 2 (36).

Al-Ansari, Ibn Hisham. 1991. Mughni Al-Labib. Edited by Muhammad Abd Al-Hamid. Beirut: Al Asriyyah Library.

Al-Bataineh, Hussein. 2019. "Emphasis Harmony in Arabic: A Critical Assessment of FeatureGeometric and Optimality-Theoretic Approaches." Languages 4 (4): 79. https://doi.org/10.3390/languages4040079.

_. 2020a. "Exclamatives Are Nonsententials: Evidence from Arabic and Other Languages." Unpublished manuscript. OSF Preprints. https://doi.org/10.31219/osf.io/k7vxw..

_. 2020b. "The Syntax of Arabic Vocatives." Brill's Journal of Afroasiatic Languages and Linguistics 1 (aop): 1-33. https://doi.org/10.1163/18776930-01202100.

Al-Bataineh, Hussein, and Phil Branigan. 2020. "The Syntax of (Complex) Numerals in Arabic." Unpublished manuscript. OSF Preprints. https://doi.org/10.31219/osf.io/6pesa.

Alhawary, Mohammad T. 2011. Modern Standard Arabic Grammar: A Learner's Guide. Somerset, United Kingdom: John Wiley \& Sons.

Al'Anbārī, 'Abū Albarkāt. 1982. Al'Inșāf F̄̄ Masā'il Alkilāf Bayn Annaḥwyīn Albaṣrȳ̄n Wa Lkawfyìn. Edited by Mạ̣ammad 'Abd Alḥamīd. Beirut, Lebanon: Almaktba Al'aṣrya.

Arnold, Bill T., and John H. Choi. 2018. A Guide to Biblical Hebrew Syntax. 2nd ed. Cambridge: Cambridge University Press.

Badawi, El Said, Michael Carter, and Adrian Gully. 2015. Modern Written Arabic: A Comprehensive Grammar. Routledge.

Benmamoun, Elabbas. 2000. The Feature Structure of Functional Categories: A Comparative Study of Arabic Dialects. New York: Oxford University Press.

Bittner, Maria, and Ken Hale. 1996. "The Structural Determination of Case and Agreement." Linguistic Inquiry 27 (1): 1-68. https://www.jstor.org/stable/4178925.

Breitbarth, Anne. 2015. "Exceptive Negation in Middle Low German.” In Webschrift for Josef Bayer, 11-15. Universität Konstanz.

Bruening, Benjamin, and Eman Al Khalaf. 2019. "No Argument-Adjunct Asymmetry in Reconstruction for Binding Condition C." Journal of Linguistics 55 (2): 247-76.

Chomsky, Noam. 2004. "Beyond Explanatory Adequacy." In Structures and Beyond: The Cartography of Syntactic Structures, Volume 3, edited by Adriana Belletti, 1 edition, 10431. Oxford; New York: Oxford University Press.

Chomsky, Noam, Ángel J. Gallego, and Dennis Ott. 2019. "Generative Grammar and the Faculty of Language: Insights, Questions, and Challenges." Catalan Journal of Linguistics, 22961.

Fintel, Kai von. 1993. "Exceptive Constructions." Natural Language Semantics 1 (2): 123-48. https://doi.org/10.1007/BF00372560. 
Fintel, Kai von, and Sabine Iatridou. 2007. “Anatomy of a Modal Construction." Linguistic Inquiry 38 (3): 445-83. https://doi.org/10.1162/ling.2007.38.3.445.

Fukui, Naoki, and Hiroki Narita. 2014. "Merge, Labeling, and Projection." In The Routledge Handbook of Syntax, edited by Andrew Carnie, Dan Siddiqi, and Yosuke Sato, 1 edition, 3-23. London: Routledge.

Gajewski, Jon. 2008. "NPI Any and Connected Exceptive Phrases." Natural Language Semantics; Dordrecht 16 (1): 69-110. http://dx.doi.org.qe2a-proxy.mun.ca/10.1007/s11050-0079025-8.

Haddad, Youssef A. 2019. “Counter-Cyclic Merge as a Last Resort for Adjuncts: Evidence from Levantine Arabic Attitude Datives." Brill's Journal of Afroasiatic Languages and Linguistics 11 (2): 316-39.

Harris, Zellig Sabbettai. 1982. A Grammar of English on Mathematical Principles. John Wiley \& Sons Incorporated.

Hasegawa, Akio, and Jean-Pierre Koenig. 2011. "Focus Particles, Secondary Meanings, and Lexical Resource Semantics: The Case of Japanese Shika." In Proceedings of the 18th International Conference on Head-Driven Phrase Structure Grammar, 81-101.

Hiraiwa, Ken. 2010. "The Syntactic OCP.” In The Proceedings of the 11th Tokyo Conference on Psycholinguistics, 35-56.

Hoeksema, Jacob. 1995. "The Semantics of Exception Phrases." In Quantifiers, Logic, and Language, edited by Jaap van der Does and Jan van Eijck, 145-177. CSLI Publications. Stanford.

Ibn Ya'īsh, Muwaffaq-Addiyn. 2001. Sharh Al-MufaSSal Lil-Zamaxsharī. Edited by 'Imīl Ya qūb. 1st ed. Vol. 4. Beirut, Lebanon: Dar Al-Kotob Al-ilmyah.

Ionescu, Emil. 2013. "Exceptive Phrases in Romanian. A Fragment-Based Analysis." In The 20th International Conference on Head-Driven Phrase Structure Grammar. Citeseer.

Khalaily, Samir. 2019. "The Exceptive Construction in Palestinian Arabic." Unpublished manuscript. Al-Qasemi College and Zefat College.

Larson, Richard K. 2014. On Shell Structure. 1 edition. New York and London: Routledge.

Lebeaux, David. 1991. "Relative Clauses, Licensing, and the Nature of the Derivation." In Perspectives on Phrase Structure: Heads and Licensing, Volume 25: Heads and Licensing, edited by Susan Rothstein and Stephen R. Anderson, 209-239. San Diego: Emerald Group Publishing Limited.

Lustig, Anton. 2010. A Grammar and Dictionary of Zaiwa (2 Vols.). BRILL.

Moltmann, Friederike. 1992. "Coordination and Comparatives." Ph.D. Dissertation, Massachusetts Institute of Technology.

_ 1995. "Exception Sentences and Polyadic Quantification." Linguistics and Philosophy 18 (3): 223-80. https://doi.org/10.1007/BF00985445.

Moutaouakil, Ahmed. 2009. "Exceptive Constructions: From the Arabic Grammatical Tradition to Functional Discourse Grammar." WPFG Special Issue, 83-96. 
Neeleman, Ad, and Hans Van de Koot. 2006. "Syntactic Haplology." The Blackwell Companion to Syntax, 685-710.

Nevalainen, Terttu. 1999. "The Facts and Nothin but: The (Non)Grammaticalization of Negative Exclusives in English." In Negation in the History of English, edited by Ingrid TiekenBoon van Ostade, Gunnel Tottie, and Wim Wurff, 167-88. Berlin, New York: Walter de Gruyter.

Norris, Mark. 2014. “A Theory of Nominal Concord.” UC Santa Cruz.

O’Neill, Katharine. 2014. "A Phonetic Study of Word-Final Phenomena in Northern East Cree." M.A. Thesis, Memorial University of Newfoundland.

O’Neill, Teresa. 2011. "The Syntax of Ne...que Exceptives in French.” University of Pennsylvania Working Papers in Linguistics 17 (1). https://repository.upenn.edu/pwpl/vol17/iss1/20.

Ouhalla, Jamal. 2013. “Agreement Unified: Arabic.” In Diagnosing Syntax, edited by Lisa LaiShen Cheng and Norbert Corver, 314-333. Oxford: Oxford University Press.

Pérez-Jiménez, Isabel, and Norberto Moreno-Quibén. 2011. "Sentential Coordination and Ellipsis: Free Exceptives in Spain." In Romance Languages and Linguistic Theory 2009: Selected Papers from "Going Romance" Nice 2009, edited by Janine Berns, Haike Jacobs, and Tobias Scheer, 255-72. Amsterdam: John Benjamins Publishing.

—. 2012. “On the Syntax of Exceptions. Evidence from Spanish.” Lingua 122 (6): 582-607. https://doi.org/10.1016/j.lingua.2012.01.001.

Potsdam, Eric, and Maria Polinsky. 2017. “A Preliminary Look at Exceptives in Tahitian.” In Asking the Right Questions: Essays in Honor of Sandra Chung, 28-36. California: University of California, Santa Cruz.

Radford, Andrew. 2009. Analysing English Sentences. Cambridge,: Cambridge University Press.

Ryding, Karin C. 2005a. A Reference Grammar of Modern Standard Arabic. Cambridge University Press.

- 2005b. A Reference Grammar of Modern Standard Arabic. 1st edition. New York: Cambridge University Press.

Sava, Nicoleta. 2009. "Altceva Decât Nu ... Decât.” Bucharest Working Papers in Linguistics XI (1): 109-18.

Soltan, Usama. 2016. "On the Syntax of Exceptive Constructions in Egyptian Arabic." In Perspectives on Arabic Linguistics XXVII, edited by Davis Stuart and Usama Soltan, 3558. Studies in Arabic Linguistics. Amsterdam; Philadelphia: John Benjamins Publishing Company. https://brill.com/view/journals/aall/10/1/article-p161_7.xml.

Sportiche, Dominique. 2019. "Somber Prospects for Late Merger.” Linguistic Inquiry 50 (2): 41624.

Weisser, Philipp. 2019. “On the Symmetry of Case in Conjunction.” Syntax.

Winchester, Lindley. 2019. "Concord and Agreement Features in Modern Standard Arabic." Glossa: A Journal of General Linguistics 4 (1): 91. https://doi.org/10.5334/gjgl.710. 
Wong, Sam Yin, Chu-Ren Huang, and I.-Hsuan Chen. 2018. "Facilitating and Blocking Conditions of Haplology: A Comparative Study of Hong Kong Cantonese and Taiwan Mandarin." In Proceedings of the 32nd Pacific Asia Conference on Language, Information and Computation.

Xiang, Yimei. 2017. “ONLY: An NPI-Licenser and NPI-Unlicenser.” Journal of Semantics 34 (3): 447-81. https://doi.org/10.1093/jos/ffx006.

Zabarah, Hana. 2017. "From Description to Prescription: The Exceptive in Arabic Grammatical Theory." Historiographia Linguistica $44 \quad$ (1): 135-63. https://doi.org/10.1075/hl.44.1.04zab.

Zewi, Tamar. 1998. "The Syntactical Status of Exceptive Phrases in Biblical Hebrew.” Biblica 79 (4): 542-48. http://www.jstor.org/stable/42614169. 